\title{
Kandelia candel Thioredoxin f Confers Osmotic Stress Tolerance in Transgenic Tobacco
}

\author{
Xiaoshu Jing ${ }^{1,2,+}{ }^{+}$, Jun Yao ${ }^{1,+}$, Xujun Ma ${ }^{3}$, Yanli Zhang ${ }^{1}$, Yuanling Sun ${ }^{1}$, Min Xiang ${ }^{4}$, \\ Peichen Hou ${ }^{5}$, Niya $\mathrm{Li}^{4}{ }^{4}$, Rui Zhao ${ }^{1}$, Jinke Li ${ }^{1}$, Xiaoyang Zhou ${ }^{1}$ and Shaoliang Chen ${ }^{1, *}$ \\ 1 Beijing Advanced Innovation Center for Tree Breeding by Molecular Design, College of Biological Sciences \\ and Technology, Beijing Forestry University, Beijing 100083, China; johncy@126.com (X.J.); \\ yaojun990@126.com (J.Y.); z585788@163.com (Y.Z.); 18003251998@163.com (Y.S.); ruizhao926@126.com (R.Z.); \\ jinkeli@bjfu.edu.cn (J.L.); zhouxiaoyang@bjfu.edu.cn (X.Z.) \\ 2 Shandong University-Helmholtz Institute of Biotechnology, State Key Laboratory of Microbial Technology, \\ School of Life Science, Shandong University, Qingdao 266237, China \\ 3 Urat Desert-Grassland Research Station, Northwest Institute of Eco-Environment and Resources, \\ Chinese Academy of Science, Lanzhou 730000, China; maxujun@lzb.ac.cn \\ 4 Department of Biology, College of Life Science, Hainan Normal University, Haikou 571158, China; \\ x8113462@163.com (M.X.); niyali6515@163.com (N.L.) \\ 5 Beijing Research Center of Intelligent Equipment for Agriculture, \\ Beijing Academy of Agriculture and Forestry Sciences, Beijing 100097, China; houpc@nercita.org.cn \\ * Correspondence: 1schen@bjfu.edu.cn; Tel.: +86-10-6233-8129 \\ + These authors contributed equally to this work.
}

Received: 11 April 2020; Accepted: 6 May 2020; Published: 8 May 2020

\begin{abstract}
Water deficit caused by osmotic stress and drought limits crop yield and tree growth worldwide. Screening and identifying candidate genes from stress-resistant species are a genetic engineering strategy to increase drought resistance. In this study, an increased concentration of mannitol resulted in elevated expression of thioredoxin $\mathrm{f}(K c \operatorname{Tr} x \mathrm{f})$ in the nonsecretor mangrove species Kandelia candel. By means of amino acid sequence and phylogenetic analysis, the mangrove Trx was classified as an f-type thioredoxin. Subcellular localization showed that KcTrxf localizes to chloroplasts. Enzymatic activity characterization revealed that KcTrxf recombinant protein possesses the disulfide reductase function. KcTrxf overexpression contributes to osmotic and drought tolerance in tobacco in terms of fresh weight, root length, malondialdehyde (MDA) content, and hydrogen peroxide $\left(\mathrm{H}_{2} \mathrm{O}_{2}\right)$ production. KcTrxf was shown to reduce the stomatal aperture by enhancing $\mathrm{K}^{+}$ efflux in guard cells, which increased the water-retaining capacity in leaves under drought conditions. Notably, the abscisic acid (ABA) sensitivity was increased in KcTr $x f$-transgenic tobacco, which benefits plants exposed to drought by reducing water loss by promoting stomatal closure. KcTr $x f$-transgenic plants limited drought-induced $\mathrm{H}_{2} \mathrm{O}_{2}$ in leaves, which could reduce lipid peroxidation and retain the membrane integrity. Additionally, glutathione (GSH) contributing to reactive oxygen species (ROS) scavenging and transgenic plants are more efficient at regenerating GSH from oxidized glutathione (GSSG) under conditions of drought stress. Notably, KcTrxf-transgenic plants had increased glucose and fructose contents under drought stress conditions, presumably resulting from KcTrxf-promoted starch degradation under water stress. We conclude that KcTrxf contributes to drought tolerance by increasing the water status, by enhancing osmotic adjustment, and by maintaining ROS homeostasis in transgene plants.
\end{abstract}

Keywords: thioredoxin; Kandelia candel; mannitol; drought; water retaining capacity; soluble sugar; $\mathrm{H}_{2} \mathrm{O}_{2}$; stomatal aperture; abscisic acid; $\mathrm{K}^{+}$flux; guard cells; noninvasive micro-test technique 


\section{Introduction}

Drought is a major natural disaster that not only reduces the crop yield but also limits the growth and productivity of forest trees [1,2]. Global warming has resulted in more frequent and extreme occurrences of drought [3,4]. Genetic engineering is considered a functional tool that enhances drought resistance in crop and tree species [2]. Screening and identifying candidate genes from stress-resistant species are a strategy for drought tolerance engineering. True mangroves along coastlines are interesting models for screening candidate genes since they are able to tolerate the extreme osmotic stress caused by the seawater level of salt [5-8]. Kandelia candel is a major mangrove species that occurs along southern China coastlines. $\mathrm{NaCl}$-altered photosynthesis, salt accumulation, ion compartmentation, and fluxes have previously been investigated in nonsecretor mangroves [9-11]. K. candel plants have an oxygen-scavenging system that acts against reactive oxygen species (ROS) under conditions of $\mathrm{NaCl}$ stress in addition to the $\mathrm{Na}^{+} / \mathrm{H}^{+}$antiport system to remain in ionic homeostasis [12-14]. K. candel increases the transcription of the $C S D$ gene which encodes a $\mathrm{Cu} / \mathrm{Zn}$ superoxide dismutase (SOD) to reduce ROS in chloroplasts over the long term and in a high saline environment [12]. Moreover, salt treatment increases the transcription of an f-type thioredoxin (Trx) in K. candel [13]. Being small and ubiquitous proteins (12-14 kD) with a conserved redox active site (WCXPC), Trxs serve as a crucial important redox regulator in higher plants [15]. These proteins are able to catalyze the reduction of disulfide bonds in many target proteins to regulate their structure and function [15]. We showed that KcTrxf-transgenic plants can scavenge the salt-elicited ROS in leaf cells through the upregulation of catalase and ascorbate peroxidase (APX) and can increase the activity of monodehydroascorbate reductase (MDAR) and glutathione reductase (GR) in the chloroplast ascorbate-glutathione (AsA-GSH) cycle [16-18], leading to an increase in reduced glutathione (GSH) and nonprotein thiols (NPTs) in the leaves [13]. Antioxidative systems also play an important role in scavenging ROS and in controlling the cellular redox potential against oxidative stress [19-21]. However, the regulatory roles of K. candel Trx family genes in osmotic and drought tolerance are not yet fully understood.

The plant water status is tightly controlled by stomatal control on transpiration and osmotic adjustment [22-24]. Stomatal regulation is one of the most important measures to reduce water loss when soil water availability to plants is limited $[25,26]$. Endogenous abscisic acid (ABA) is rapidly produced upon water deficit, osmotic, and salt stress [27-31], initiating a signaling cascade that results in stomatal closure [32-36]. Stomatal closure requires potassium $\left(\mathrm{K}^{+}\right)$to exit from the guard cells [34]. The outward-rectifying $\mathrm{K}^{+}$channels mediate the $\mathrm{K}^{+}$flow in the plasma membrane (PM) of guard cells [34,35]. ABA results in depolarization of PM, which deactivates inward-rectifying $\mathrm{K}^{+}$channels but stimulates outward-rectifying $\mathrm{K}^{+}$channels, resulting in $\mathrm{K}^{+}$efflux from guard cells [34,35]. The $\mathrm{K}^{+}$efflux from guard cells contributes to a loss of guard cell turgor and to stomatal closing [36]. Histochemical localization of $\beta$-glucuronidase (GUS) expression at the PsTRXf1:GUS promoter revealed that pea chloroplastic Trxf is expressed in guard cells [37]. However, the roles of K. candel Trxf in the regulation of the stomatal aperture and ABA response remain to be clarified.

Mangroves possess more potential ability to carry out osmotic adjustment to maintain cell turgor under osmotic stress [5,6]. K. candel tends to accumulate $\mathrm{Na}^{+}$within the cytoplasm, vacuoles, and chloroplasts in leaves $[9,14]$. This helps the mangrove to maintain a positive turgor pressure under osmotic conditions $[5,6,38]$. Moderate drought results in increased concentrations of soluble carbohydrates and polyols, which potentially promotes the maintenance of cell turgor in Populus euphratica leaves through increased osmotic pressure [39]. It is noteworthy that the concentrations of amino acids, in particular, proline, increase drastically in both water- and salt-stressed poplars [40-44]. Type-f thioredoxins have various functions in the mediation of carbon metabolism [15,45-49]. Overexpression of NtTrx $f$ increases starch accumulation in tobacco leaves [45], and knockout of AtTrx f1 decreases the starch content in the leaves of Arabidopsis thaliana mutants [46]. In contrast, thioredoxin $\mathrm{f}$ has been proposed to participate in a redox-regulated pathway of starch degradation under specific stress conditions [47-49]. For example, thioredoxin-regulated $\beta$-amylase (BAM1) triggers diurnal starch degradation in guard and mesophyll cells under conditions of osmotic stress [48]. 
Little is known about the role of $K$. candel Trxf in the regulation of carbon metabolism in response to osmotic stress.

The objective of this study was to explore the role of KcTrxf in plants adapting to water-limited environments. In this study, the Trxf gene was cloned from the nonsecretor mangrove species Kandelia candel. Subcellular localization analysis revealed that KcTrxf localized to the chloroplasts. The promoter activity of KcTrxf was investigated by GUS reporter gene expression in transgenic Arabidopsis. Trx activity was analyzed using the purified recombinant KcTrxf protein. KcTrxf was transferred to Nicotiana tabacum to clarify its role in the modulation of osmotic and drought tolerance. The leaf water-retaining capacity; stomatal aperture; malondialdehyde (MDA) content; $\mathrm{H}_{2} \mathrm{O}_{2}$ production; $\mathrm{GSH}$ and oxidized glutathione (GSSG) contents; and contents of soluble sugars, such as sucrose, glucose, and fructose, were examined under conditions of osmotic or drought stress. Furthermore, the stomatal sensitivity to ABA and $\mathrm{K}^{+}$flux in the PM of guard cells was compared between wild-type and KcTrxf-overexpressing plants. Our data showed that KcTrxf contributes to the maintenance of water status by increasing stomatal sensitivity and by enhancing osmotic adjustment, which helps the transgene plants to limit $\mathrm{H}_{2} \mathrm{O}_{2}$ production under drought conditions. The increased ratio of GSSG/GSH in KcTrxf-transgenic plants indicates that GSH contributes to ROS scavenging under conditions of drought stress. Consequently, the negative consequences of stress-induced ROS are alleviated in droughted plants.

\section{Results}

\subsection{Expression Profile of KcTrxf Following Exposure to Mannitol in Kandelia Candel Leaves}

To determine the possible involvement of KcTrxf in response to osmotic stress, the expression pattern was analyzed by real-time quantitative PCR (Figure 1). The exposure to osmotic stress caused by mannitol at $200 \mathrm{mM}, 500 \mathrm{mM}$, or $1.0 \mathrm{M}$ resulted in elevated KcTrxf expression (Figure 1). The pattern of osmotic stress-induced KcTrxf after short-term ( $8 \mathrm{~h}$, Figure 1A) treatment was similar to that following long-term exposure ( 3 days, Figure 1B). The expression of KcTrxf increased as the concentration of mannitol increased, reaching the highest level at $1.0 \mathrm{M}$ (2.5-3.2-fold) (Figure 1). This result shows that KcTrxf expression is induced by osmotic stress in the mangrove species.
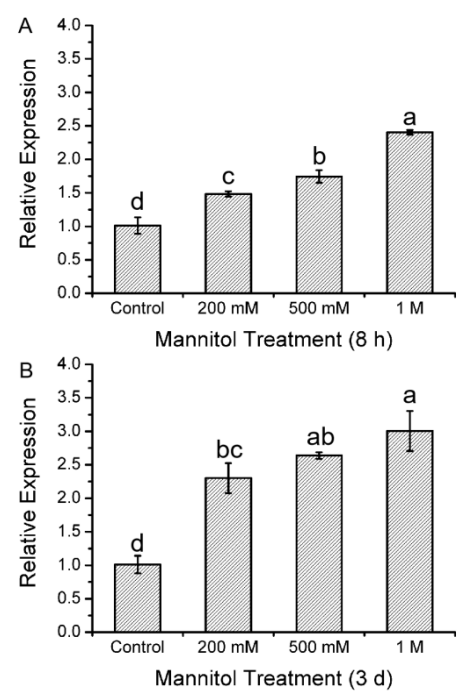

Figure 1. Expression level of the thioredoxin $\mathrm{f}(K c \operatorname{Tr} x f)$ gene in Kandelia candel leaves following mannitol treatment: Kandelia candel seedlings were exposed to 0,200 mM, $500 \mathrm{mM}$, or $1.0 \mathrm{M}$ of mannitol in Hoagland nutrient solution for $8 \mathrm{~h}$ (A) or 3 days (B). Then, the upper leaves were collected for real-time quantitative polymerase chain reaction (PCR) analysis. Expression levels of KcTrxf were normalized to the Kandelia candel housekeeping gene, Tublin, as an internal reference. Each column corresponds to the mean of three individual plants, and bars represent the standard error of the mean. Columns labeled with different letters, $\mathrm{a}, \mathrm{b}, \mathrm{c}$, and $\mathrm{d}$, represent significant differences at $p<0.05$ between the wild-type (WT) and transgenic lines. 


\subsection{KcTrxf Cloning and Sequence Analysis}

The 585-bp full-length cDNA of KcTrxf was cloned from K. candel leaves. The cDNA sequence encoded a putative protein of 194 amino acids (Figure 2A). The protein contains the canonical active site-WCGPC motif. Multiple sequence alignment revealed that KcTrxf displays high identity with the Trxfs in other plant species (Figure 2A). KcTrxf showed that 55.84\% identifies with AtTrxf1 and that $56.35 \%$ identifies with AtTrxf2. The constructed phylogenetic tree showed the conservation of KcTrxf to other Trxfs (Figure 2B). Therefore, KcTrxf was classified as an f-type thioredoxin.

A AtTrxf1
AtTrxf2
PtTrxf
KcTrxf


AtTrxf1
AtTrxf2
PtTrxf
KcTrxf
AtTrxf 1
AtTrxf2
PtTrxf
KcTrxf

AtTrxf1
AtTrxf2
PtTrxf
KcTrxf
AtTrxf1
AtTrxf2
PtTrxf
KcTrxf
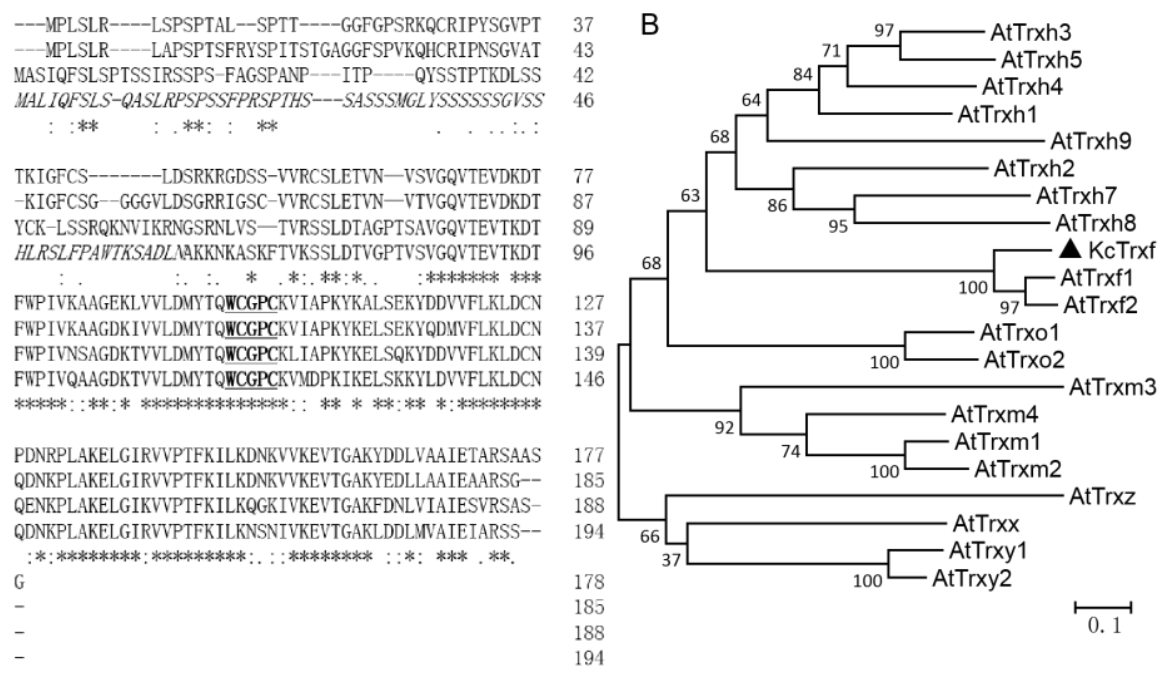

Figure 2. Amino acid sequence and phylogenetic analysis of KcTrxf: (A) Multiple sequence alignment of KcTrxf with Trxfs from other species. Amino acid sequences of Trxf were deduced from Kandelia candel (KcTrxf), Populus trichocarpa (PtTrxf), and Arabidopsis thaliana chloroplasts (AtTrxf1 and AtTrxf2). Asterisks $\left({ }^{*}\right)$ and dots $(\cdot,:)$ indicate identical and conserved amino acid residues, respectively. Italics represent chloroplast transit peptides. Active sites are underlined and in bold. (B) Phylogenetic relationships between KcTrxf and other Trx family members from different species. The phylogenetic tree was constructed with the neighbor-joining method using MEGA 5. Bootstrap values of 1000 replicates are presented.

\subsection{Subcellular Localization of KcTrxf}

The subcellular location predicted by TargetP [50] indicated that K. candel Trxf might be localized to chloroplasts, and ChloroP [51] predicted that a chloroplast transit peptide of 62 amino acid is cleaved (Figure 2A). To confirm the localization of $K$. candel Trxf, a construct containing a translational fusion of its open reading frame to the green fluorescent protein (GFP) reporter gene at its $C$ terminus was transiently expressed in Arabidopsis protoplasts and imaged using confocal laser microscopy. The fluorescence emitted by the GFP reporter of the fusion construct was targeted to the chloroplast, showing punctate structures in the chloroplast (Figure 3). The KcTrxf location is consistent with our previous report in a salt study, where KcTrxf was shown to be a typical thioredoxin in the chloroplast [13]. The vector control pEZS-NL did not express GFP without adding a coding sequence to the $5^{\prime}$ end of the open reading frame [13].

\subsection{KcTrxf Promoter:GUS Fusion in Transgenic Arabidopsis Plants}

To examine the contribution of the $5^{\prime}$ region of KcTrxf genes to the regulation of expression, extensions of $5^{\prime}$ flanking sequences of KcTrxf fused to the GUS reporter gene were expressed in Arabidopsis. Specific expression in guard cells was confirmed in GUS plants (Figure 4). Our data is in agreement with that obtained by de Dios Barajas-Lopez et al. (2007) [37], who found that the promoter of pea thioredoxin $\mathrm{f}$ is active in guard cells of transgenic Arabidopsis. Furthermore, GUS activity was 
observed in mesophyll cells in addition to in guard cells (Figure 4). The staining of mesophyll cells reduced the appearance of GUS in guard cells (Figure 4). Similarly, strong GUS expression was also seen in the leaves of PsTRXf1::GUS promoter transgenic Arabidopsis plants [37].
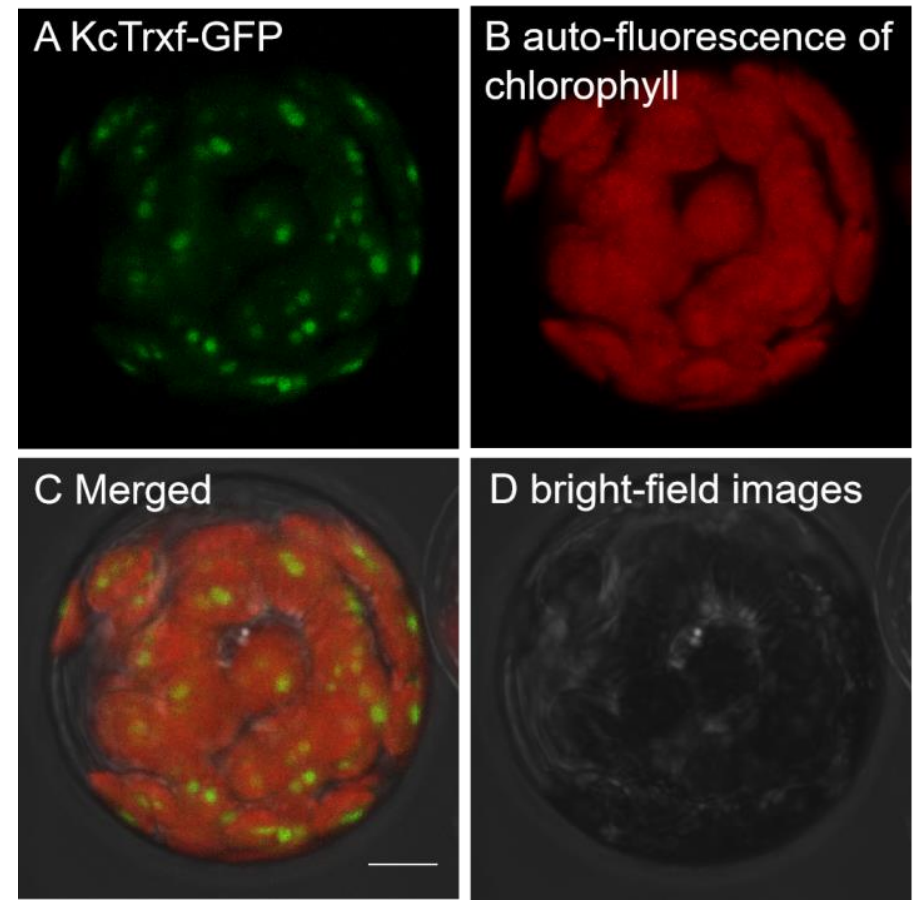

Figure 3. Subcellular localization of KcTrxf in Arabidopsis mesophyll protoplasts: Representative images of green fluorescence of KcTrxf-GFP (A) and red autofluorescence of chlorophyll (B) were monitored separately using a confocal laser scanning microscope and the two colored fluorescence images were merged (C). (D) Bright-field images. Bar $=10 \mu \mathrm{m}$.

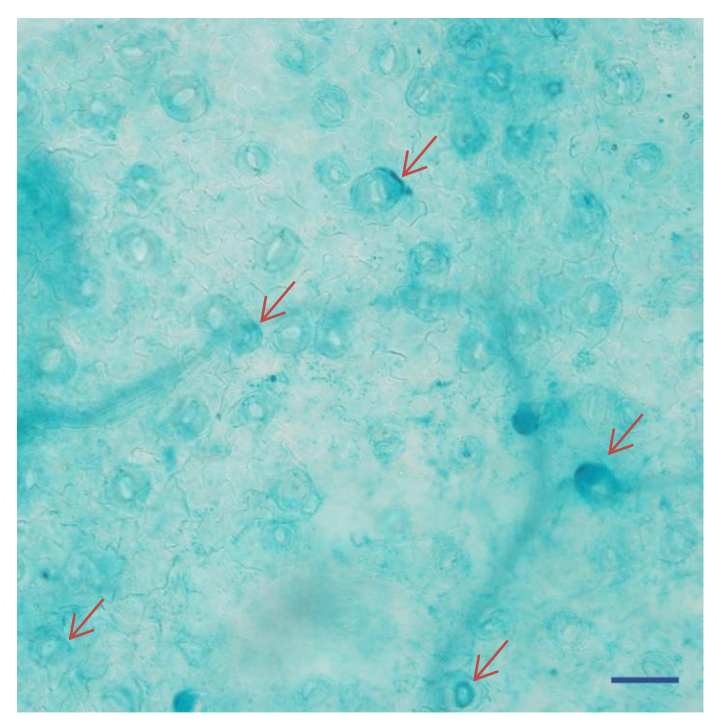

Figure 4. Histochemical localization of $\beta$-glucuronidase (GUS) expression in guard cells under the control of the KcTrxf promoter in transgenic Arabidopsis plants: The representative figure shows a typical expression pattern obtained from two independent experiments. The arrows indicate the dense staining of several guard cells. Bar $=100 \mu \mathrm{m}$. 


\subsection{Purification of Recombinant KcTrxf Protein and Trx Activity}

It has been shown that the peculiar character of $\operatorname{Trx}$ proteins has a disulfide reductase function [52-54]. Using dithiothreitol (DTT) as the reductant, the intermolecular disulfide bonds between the insulin A and B chains can be reduced by Trx. Precipitation of the insoluble B chain can be measured photometrically by an increase in the absorbance at $650 \mathrm{~nm}$ [55]. Therefore, to determine whether $K$. candel Trxf possesses disulfide reductase activity, the proteins were expressed in E. coli to obtain recombinant proteins. The recombinant proteins were purified by sephadex gel filtration and analyzed with sodium dodecyl sulfate-polyacrylamide gel electrophoresis (SDS-PAGE). KcTrxf accumulated at a high level in the soluble fraction after isopropylthythio- $\beta$-galactoside (IPTG) induction and was purified to homogeneity (Figure 5A).
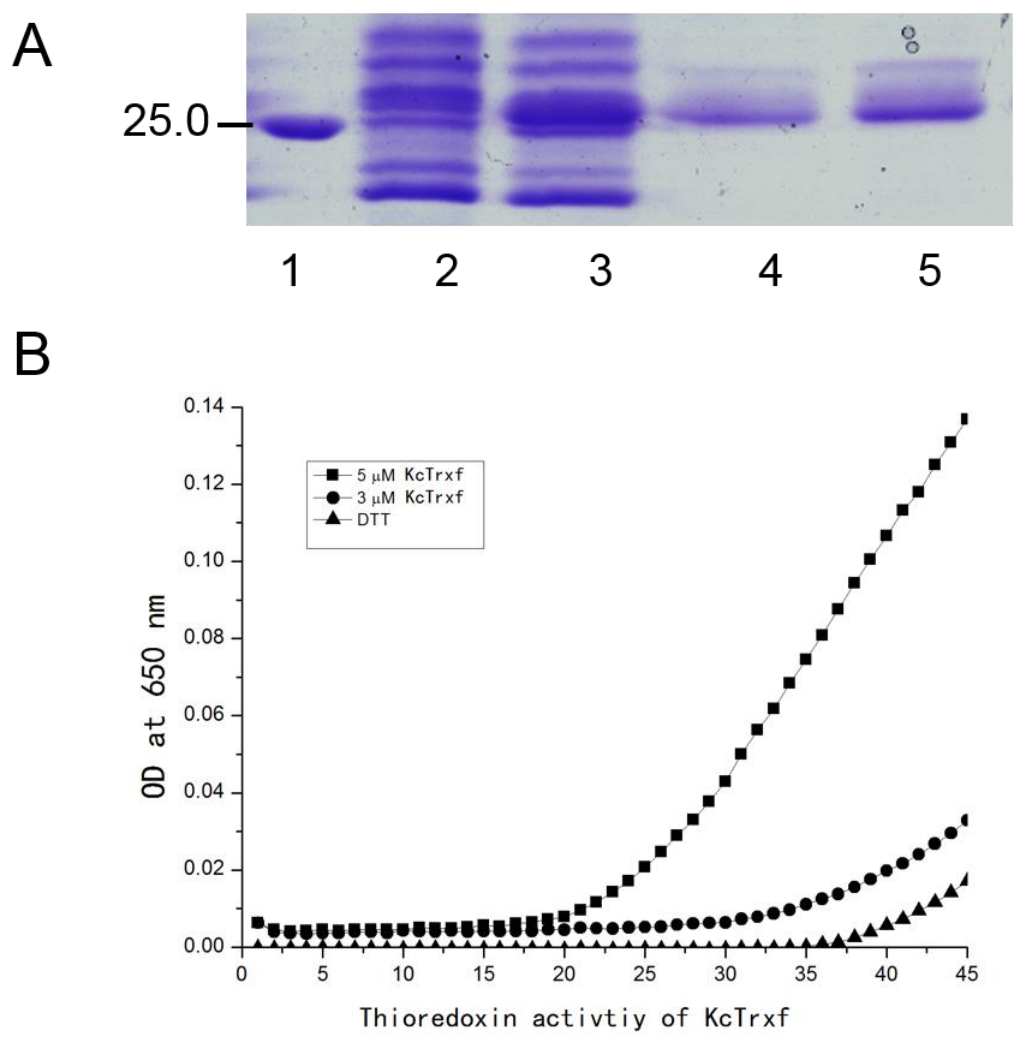

Figure 5. Purification of KcTrxf recombinant protein and thioredoxin activity assay. (A) SDS-PAGE of KcTrxf recombinant protein: Crude extract of Escherichia coli transformed with Pet28a-KcTrxf before (Lane 2) and after IPTG induction (Lane 3). KcTrxf was purified by sephadex gel filtration (Lanes 4 and 5). Molecular weight markers (Lane 1) are shown in kilodaltons. (B) The activity of the KcTrxf protein determined by insulin disulfide reduction assay: The reduction of insulin was measured by an increase in turbidity at $650 \mathrm{~nm}$ because of insulin precipitation. The reaction containing $3 \mu \mathrm{M} \mathrm{KcTrxf}(\bullet)$ and $5 \mu \mathrm{M} \mathrm{KcTrxf}(\boldsymbol{\square})$ began by dithiothreitol (DTT) addition. The nonenzymatic insulin reduction by DTT alone $(\boldsymbol{\Lambda})$ was used as a negative control.

Then, the activity of the recombinant protein was determined by reducing insulin-disulfide bridges in the presence of dithiothreitol (DTT) [55]. Compared with the negative control (DTT alone), the addition of recombinant protein resulted in an abrupt increase in turbidity at $650 \mathrm{~nm}$ (Figure 5B), indicating a reduction of insulin, as described previously [55]. In the reaction mixture, Trx activity increased with the concentration of KcTrxf recombinant protein from 3 or $5 \mu \mathrm{M}$ (Figure 5B). 


\subsection{Overexpression of KcTrxf in Tobacco and Phenotype Tests}

To testify the importance of KcTr $x f$ under conditions of osmotic and drought tolerance, KcTr $x f$ was transferred to tobacco under the control of the CaMV $35 \mathrm{~S}$ promoter. Phenotypic screening was carried out using seedlings grown on MS medium and rooted plants acclimated to nursery soil. In brief, the following steps were carried out:

(i) Seven-day-old seedlings grown on MS medium were transferred to MS medium supplemented with $250 \mathrm{mM}$ mannitol. After 14 days of mannitol treatment, the wild-type (WT) plants exhibited osmotic injury, e.g., smaller dark green leaves with slight curled edges (Figure 6A). No obvious injury symptom was observed in KcTrxf-transgenic plants (Figure 6A). The transgenic plants displayed higher root lengths and fresh weights than WT under mannitol treatment (Figure 6B,C). There were no significant differences between WT and transgenic plants in terms of root length and fresh weight under normal growth conditions (Figure 6B,C).

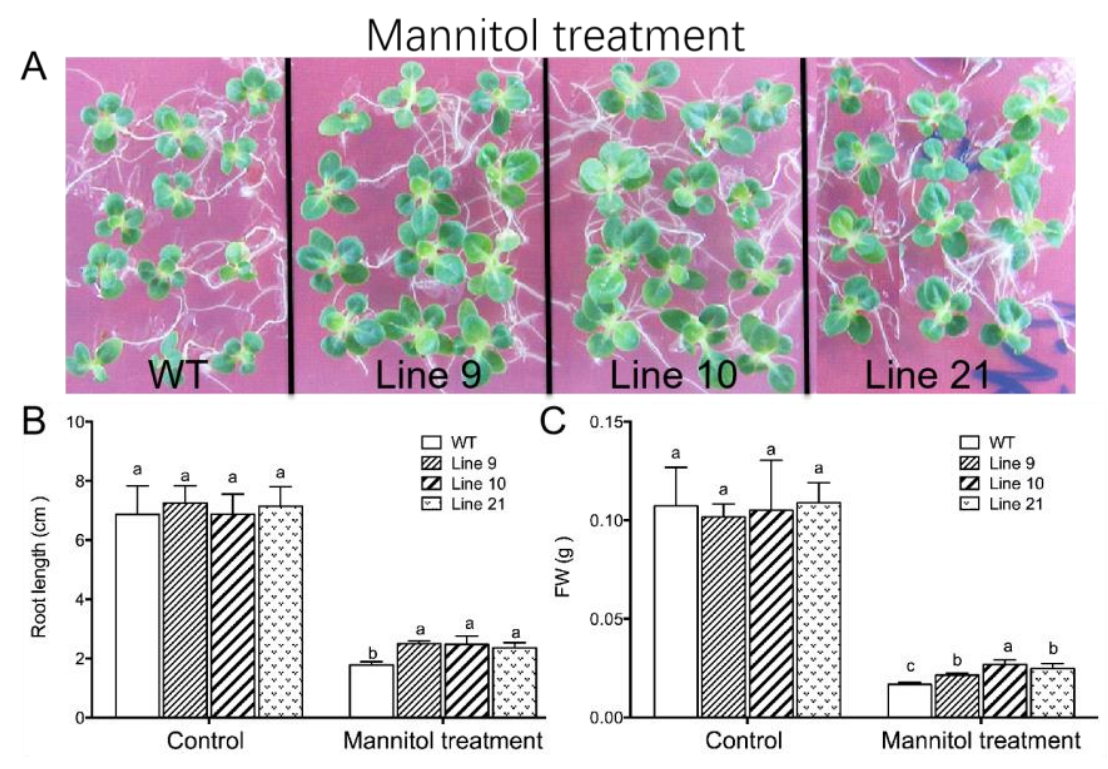

Figure 6. Phenotype tests of wild-type tobacco and $K c \operatorname{Tr} x f$-transgenic seedlings under osmotic treatment: Seeds of wild-type (WT) and transgenic lines (L9, L10, and L21; T2 generation) were germinated on MS medium for 7 days and then subjected to 0 - or 250-mM mannitol for 14 days. Then, the root lengths and fresh weights of whole seedlings from WT and transgenic plants were measured. (A) Representative images showing plant performance after exposure to mannitol for 14 days. $(\mathbf{B}, \mathbf{C})$ The root growth and fresh weight of tobacco seedlings: In Figure 6B,C, each column is the mean of 12-20 individual plants and bars represent the standard error of the mean. Columns labeled with different letters, $a, b$, and c, represent significant differences between WT and transgenic lines at $p<0.05$.

(ii) In a drought test, four-week-old seedlings were transferred and acclimated to nursery soil for four weeks. All genotypes were subjected to water stress by withholding water for two weeks. Following drought treatment, the wild-type plants wilted whereas $K c \operatorname{Tr} x f$-transgenic plants showed no sign of wilting (Figure 7A). Collectively, the phenotype tests showed that KcTrxf enhanced plant tolerance to osmotic stress and drought stress.

To determine whether KcTrxf alleviated drought-induced oxidative damage, malondialdehyde (MDA), a marker of lipid peroxidation, was measured. The MDA content increased significantly in the wild-type plants during drought treatment, while MDA remained at low levels in transgenic plants (Figure 7D). This indicates that the membrane integrity of transgenic plants was less disrupted by lipid peroxidation.

$\mathrm{H}_{2} \mathrm{O}_{2}$ levels were measured, as ROS might contribute to drought-induced lipid peroxidation in WT plants. $\mathrm{H}_{2} \mathrm{O}_{2}$ levels induced by drought were significantly higher in WT plants than in transgenic 
plants (Figure 7E), suggesting that KcTrxf was able to regulate ROS homeostasis and to reduce the oxidative damage caused by drought stress.
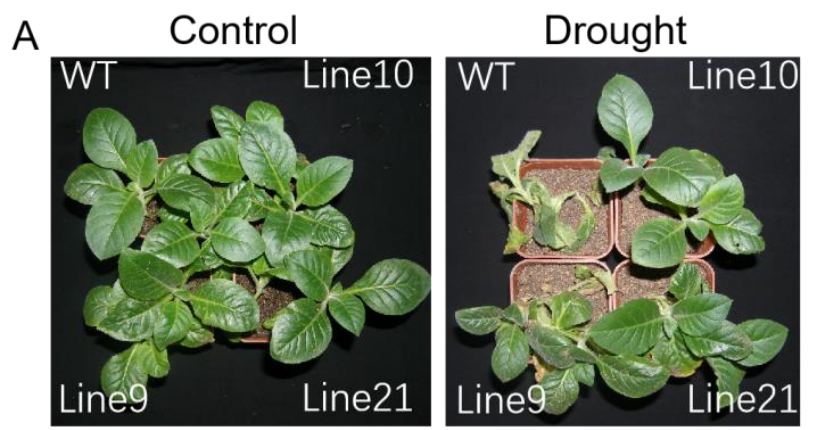

B
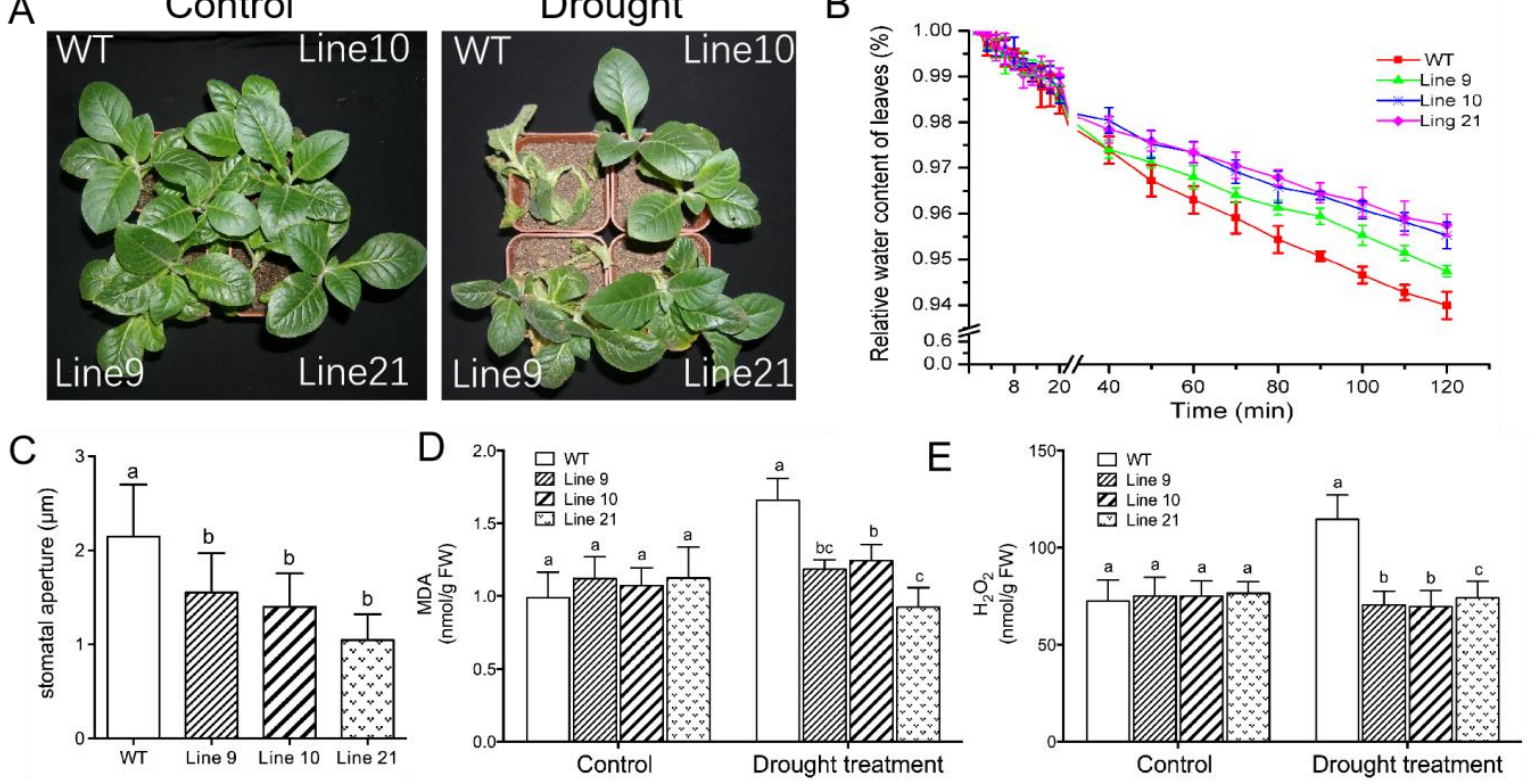

Figure 7. Phenotype tests of wild-type tobacco and KcTrxf-transgenic seedlings under conditions of drought stress: Four-week-old rooted plants on MS of WT and transgenic lines (L9, L10, and L21) were transferred to nursery soil for 4 weeks of acclimation and then exposed to drought treatment by withholding water for 2 weeks. (A) Representative images showing plant performance after exposure to drought stress for 14 days. (B) Water-retaining capacity (WRC): Fully opened leaves were sampled from WT and transgenic plants, and the WRC of the detached leaves was measured after exposure to air for $120 \mathrm{~min}$. Each value is the mean of four individual plants, and bars represent the standard error of the mean. (C) Stomatal aperture: Epidermal peels were stripped from air-exposed leaves and used for stomatal aperture measurement. Each column is the mean of 100 stomata from four individual plants, and the bars represent the standard error of the mean. (D) Malondialdehyde (MDA) content. (E) $\mathrm{H}_{2} \mathrm{O}_{2}$ production. After 14 days of drought treatment, plants were harvested from WT and transgenic plants to measure MDA and $\mathrm{H}_{2} \mathrm{O}_{2}$ production. In Figure $7 \mathrm{C}-\mathrm{E}$, columns labeled with different letters, $\mathrm{a}, \mathrm{b}$, and $\mathrm{c}$, represent significant differences between WT and transgenic lines at $p<0.05$.

Being an important antioxidant in the AsA-GSH cycle, glutathione plays important roles in antioxidative defense in stressed plants [17-19]. Drought treatment decreased the GSH content in WT but increased the oxidized glutathione (GSSG) content, which led to an increase in the GSSG/GSH ratio (49\%, Table 1). GSH was less affected by drought in KcTrxf-transgenic lines, although a typically low GSH content was observed under control conditions (Table 1). Drought induced an increase in the GSSG/GSH ratio by $9-35 \%$ due to the increased GSSG content in the transgenic lines of stressed plants.

\subsection{KcTrxf Overexpression Increases Water-Retaining Capacity and Stomatal Sensitivity to ABA}

Maintaining the water status is crucial for plants to adapt to a drought environment. The water-retaining capacity (WRC), which reflects the plant's ability to control water loss under drought, was examined in both WT tobacco and KcTrxf-transgenic lines. The transgenic plants exhibited typically higher WRC than the wild-type plants after $2 \mathrm{~h}$ of air exposure (Figure 7B). These results indicate that the transgenic plants can retain their water content in response to drought stress.

The lower water loss in transgenic lines was, at least in part, due to closure of the stomata [56]. During the period of air exposure, the stomatal apertures in the transgenic plants were $36 \%-44 \%$ lower 
than in wild-type seedlings (Figure 7C). The low stomatal apertures reduced water loss during the period of air exposure in transgene plants.

Table 1. The contents of glutathione (GSH) and oxidized glutathione (GSSG) and the ratio of GSSG/GSH in leaves of wild-type tobacco and KcTrxf-transgenic seedlings under conditions of drought stress: Four-week-old rooted plants on the MS of WT and transgenic lines (L9, L10, and L21) were transferred to nursery soil for 4 weeks of acclimation and then exposed to drought treatment by withholding water for 2 weeks. Control and stressed plants were harvested from WT and transgenic lines to measure GSH and GSSG contents. Each value $( \pm \mathrm{SD})$ is the mean value of four individual plants, and values labeled with different letters, a, b, and c, represent significant differences between WT and transgenic lines at $p<0.05$.

\begin{tabular}{cccc}
\hline & Lines & Control & Drought \\
\hline \multirow{4}{*}{ GSH } & WT & $28.01 \pm 0.16^{\mathrm{a}}$ & $24.34 \pm 0.71^{\mathrm{a}}$ \\
& Line 9 & $16.50 \pm 0.38^{\mathrm{c}}$ & $17.68 \pm 0.17^{\mathrm{b}}$ \\
& Line 10 & $15.57 \pm 0.65^{\mathrm{c}}$ & $15.38 \pm 0.72^{\mathrm{b}}$ \\
& Line 21 & $20.87 \pm 0.38^{\mathrm{b}}$ & $15.91 \pm 0.24^{\mathrm{b}}$ \\
\hline \multirow{3}{*}{ GSSG } & WT & $16.48 \pm 0.73^{\mathrm{b}}$ & $21.40 \pm 0.92^{\mathrm{a}}$ \\
& Line 9 & $18.87 \pm 0.44^{\mathrm{ab}}$ & $21.97 \pm 0.87^{\mathrm{a}}$ \\
& Line 10 & $18.42 \pm 0.68^{\mathrm{ab}}$ & $21.55 \pm 0.11^{\mathrm{a}}$ \\
& Line 21 & $19.51 \pm 0.77^{\mathrm{a}}$ & $20.11 \pm 0.71^{\mathrm{a}}$ \\
\hline \multirow{3}{*}{ GSSG/GSH } & WT & $0.59 \pm 0.02^{\mathrm{c}}$ & $0.88 \pm 0.02^{\mathrm{b}}$ \\
& Line 9 & $1.14 \pm 0.03^{\mathrm{a}}$ & $1.24 \pm 0.04^{\mathrm{a}}$ \\
& Line 10 & $1.18 \pm 0.05^{\mathrm{a}}$ & $1.40 \pm 0.06^{\mathrm{a}}$ \\
& Line 21 & $0.93 \pm 0.04^{\mathrm{b}}$ & $1.26 \pm 0.05^{\mathrm{a}}$ \\
\hline
\end{tabular}

\subsection{Drought-Induced $K^{+}$Fluxes in Guard Cells}

Drought-induced stomatal closing is mediated by soluble osmolytes, for example $\mathrm{K}^{+}$, in the guard cells [36]. The $\mathrm{K}^{+}$flux was measured in guard cells, since stomatal closure requires potassium to exit from the PM of guard cells [33]. Noninvasive micro-test technique (NMT) flux data revealed that guard cells of the transgenic plants exhibited a greater net $\mathrm{K}^{+}$efflux than wild-type plants after drought stress (Figure 8).

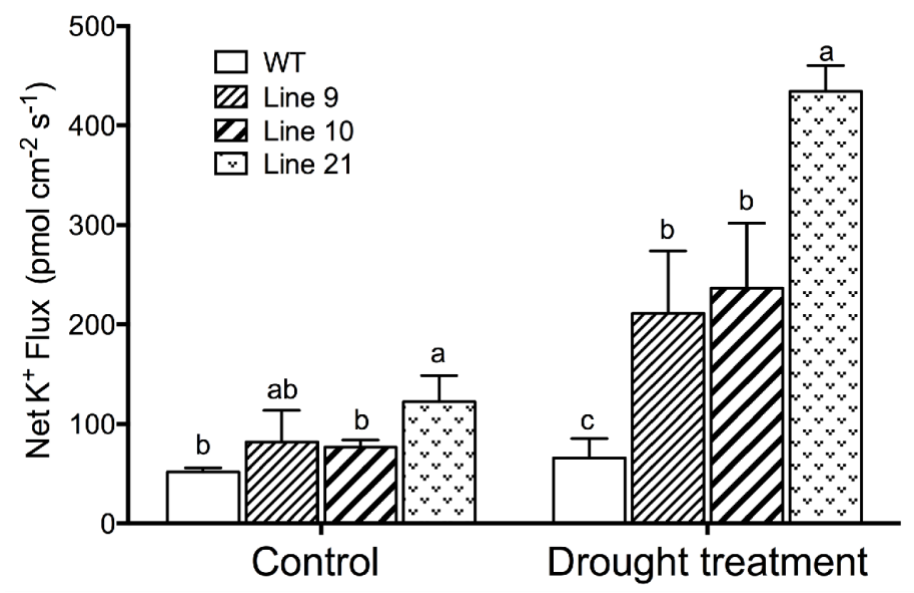

Figure 8. Steady $\mathrm{K}^{+}$flux profiles in guard cells of WT and transgenic lines under drought treatment: Four-week-old rooted plants on the MS of WT and transgenic lines (L9, L10, and L21) were transferred to nursery soil for 4 weeks of acclimation and then exposed to drought treatment by withholding water for 2 weeks. The $\mathrm{K}^{+}$fluxes in guard cells were measured using the noninvasive micro-test technique (NMT). Each column is the mean of 30-40 stomata from four individual plants, and bars represent the standard error of the mean. Columns labeled with different letters, a, b, and c, represent significant differences between WT and transgenic lines at $p<0.05$. 


\subsection{KcTrxf Overexpression Increases Stomatal Sensitivity to ABA}

The phytohormone abscisic acid (ABA) induces stomatal closure, which is crucial for plant adaptation to water stress conditions [2]. To determine whether KcTrxf is involved in the ABA signaling pathway, the sensitivity to ABA was examined in $K c \operatorname{Tr} x f$-transgenic plants. At the tested dose $(5 \mu \mathrm{M})$, abscisic acid increased stomatal closure in all tested lines, but a more pronounced enhancement was observed in transgenic lines (Figure 9A,B).

\section{$-\mathrm{ABA}$}
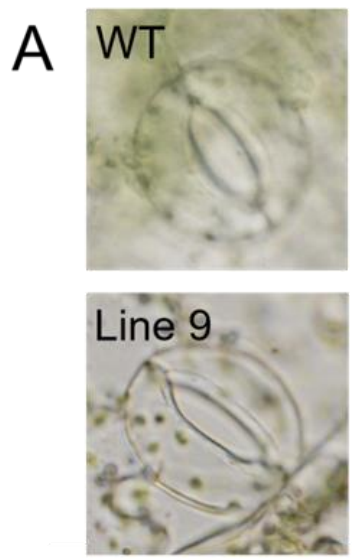

$\mathrm{B}$

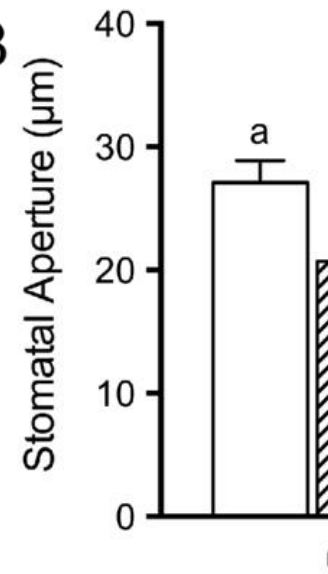

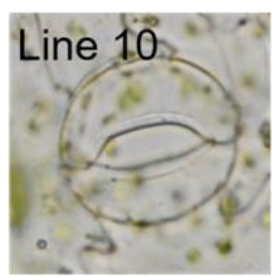

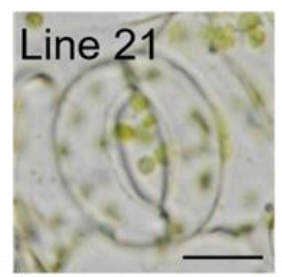

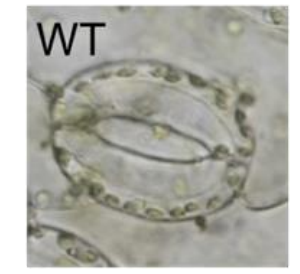
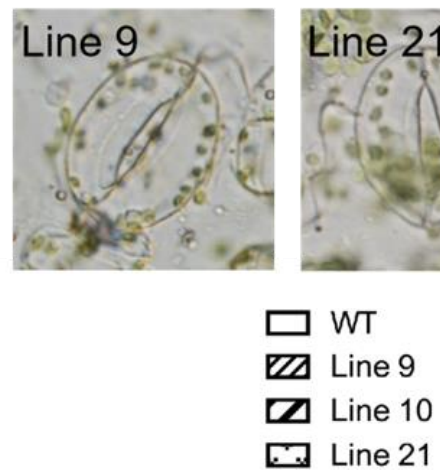

$+\mathrm{ABA}$
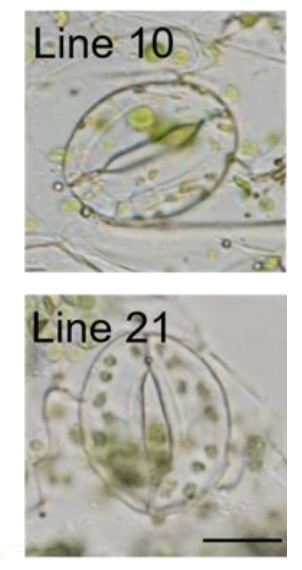

\section{a}

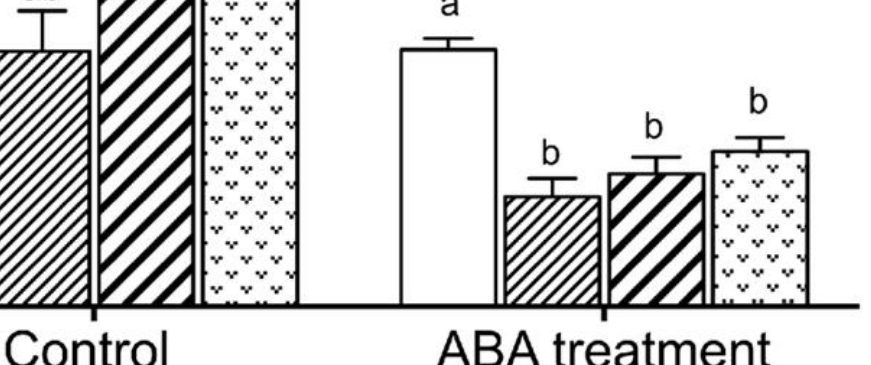

Figure 9. Abscisic acid (ABA)-induced stomatal closure in wild-type (WT) and KcTrxf-transgenic lines: Wild-type tobacco and KcTr $x f$-transgenic seedlings were subjected to 0 or $5 \mu \mathrm{M}$ ABA treatment for $2 \mathrm{~h}$ after leaves were illuminated with cool light $\left(150 \mu \mathrm{mol} \mathrm{m} \mathrm{m}^{-2} \mathrm{~s}^{-1}\right)$ for $2 \mathrm{~h}$ to induce stomatal opening. Thereafter, epidermal peels were stripped from fully opened leaves of WT and KcTr $x f$-transgenic Arabidopsis lines (L9, L10, and L21). Stomatal apertures were measured in epidermal peels treated with or without ABA. (A) Representative images showing stomata before and after ABA treatment. Scale bar: $50 \mu \mathrm{m}$. (B) Stomatal aperture: Each column is the mean of 100 stomata from four individual plants, and bars represent the standard error of the mean. Columns labeled with different letters, a, and $\mathrm{b}$, represent significant differences at $p<0.05$ between WT and transgenic lines.

\subsection{KcTrxf Increases Glucose and Fructose but Decreased Sucrose under Drought}

Soluble sugars, such as sucrose, glucose, and fructose, contribute to osmotic adjustment under drought conditions [57]. Concentrations of sucrose, glucose, and fructose were also measured in response to drought stress. Under control conditions, the concentrations of glucose and fructose were essentially similar in all genotypes (Figure 10). The content of sucrose in the transgenic seedlings was typically lower than that in the WT seedlings (Figure 10). However, both glucose and fructose contents increased in the transgenic plants following drought stress and were higher than those in 
the wild-type plants (Figure 10B,C). In contrast to hexose, the sucrose content markedly decreased in drought-stressed plants of WT and transgenic lines (Figure 10A).
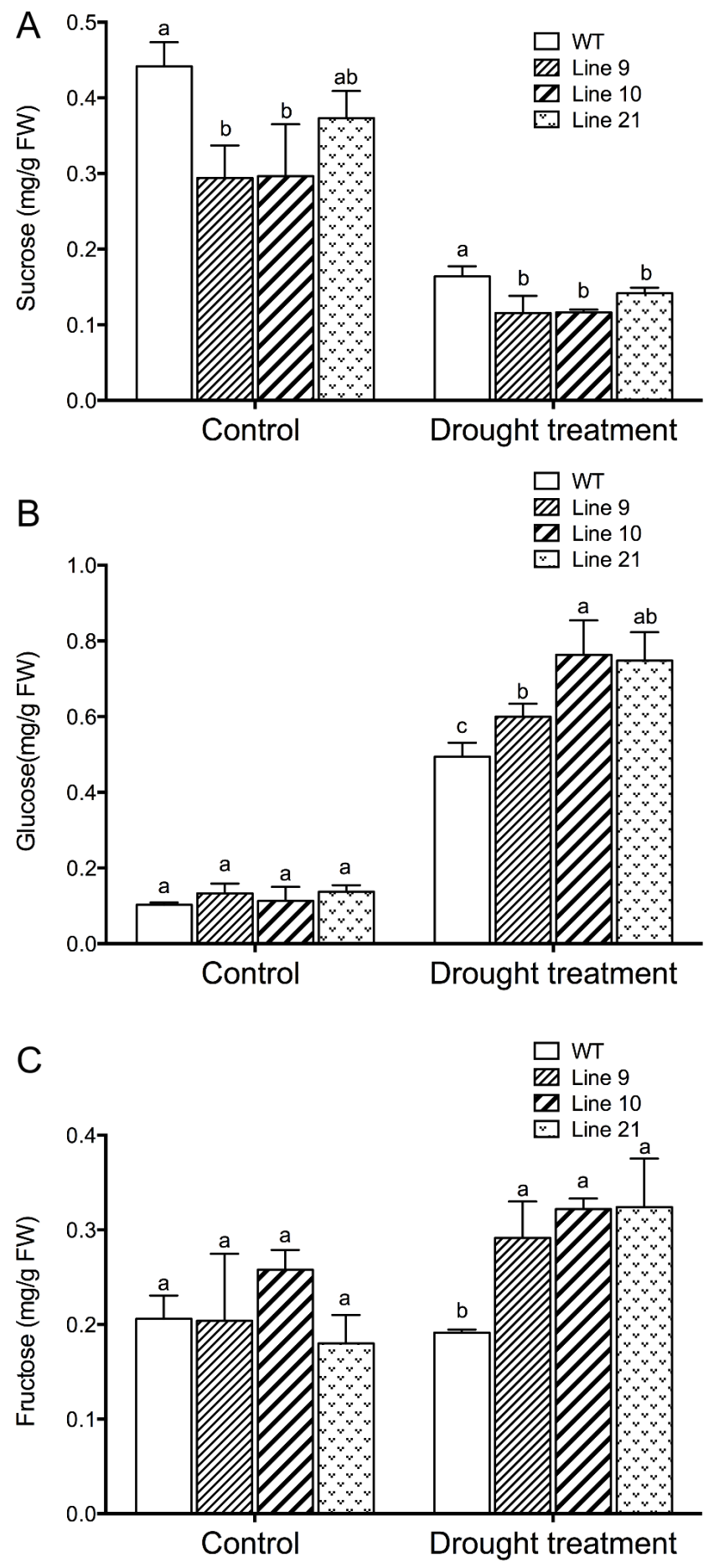

Figure 10. Sucrose, glucose, and fructose concentrations in the leaves of WT and transgenic lines under drought treatment: Four-week-old rooted plants on the MS of WT and transgenic lines (L9, L10, and L21) were transferred to nursery soil for 4 weeks of acclimation and then exposed to drought treatment by withholding water for 2 weeks. Leaves were sampled from control and water-stressed plants for sucrose (A), glucose (B), and fructose (C) measurements. Each column is the mean of 4-6 individual plants, and bars represent standard error of the mean. Columns labeled with different letters, $a$, and $b$, represent significant differences between WT and transgenic lines at $p<0.05$. 


\section{Discussion}

In this study, we confirmed the novel role of K. candel KcTrxf in the plant response to osmotic and drought stress. Phylogenetic analysis indicated that KcTrxf, with the canonical active site-WCGPC motif, is most homologous to Trxf orthologs (Figure 2). The KcTrxf protein was shown to localize to the chloroplast (Figure 3). Histochemical analysis of GUS expression showed that the KcTrxf promoter drives the expression of reporter genes in guard cells (Figure 4). Similarly, the promoter of pea thioredoxin $\mathrm{f}$ was shown to be active in the guard cells of transgenic Arabidopsis [37]. Enzymatic activity characterization revealed that KcTrxf recombinant protein possesses a disulfide reductase function, whereby it reduces the intermolecular disulfide bonds (Figure 5) [52-54].

Transcription analyses indicated that KcTrxf was upregulated by mannitol in K. candel leaves (Figure 1), suggesting that KcTrxf may contribute to osmotic tolerance. KcTrxf was overexpressed in tobacco to investigate its role in osmotic and drought tolerance. Our data from seedlings grown on MS medium and rooted plants acclimated to nursery soil showed that the tobacco plants overexpressing KcTrxf had enhanced osmotic and drought tolerance in terms of phenotypic screening. KcTrxf-transgenic plants exhibited greater root lengths and fresh weights under conditions of osmotic stress (Figure 6). Moreover, the KcTr $x f$-transgenic plants displayed less symptoms of wilting as compared to the wild-type plants under drought (Figure 7). These results show that KcTrxf enhances plant tolerance to osmotic stress and drought stress. Physiological data showed that enhanced tolerance of KcTrxf-transgenic plants mainly resulted from the increased ability to carry out stomatal control, osmotic adjustment, and ROS regulation under stress conditions.

The KcTrxf transgenic lines exhibited typically higher WRC than the wild-type plants during the period of air exposure (Figure 7). The lower water loss in transgenic lines resulted from the decreased stomatal aperture (Figure 7). As a result, the KcTr $x f$-transgenic plants were able to control the water content; consequently, leaf wilting was alleviated under drought conditions (Figure 7). NMT flux showed that KcTrxf-transgenic plants retained high $\mathrm{K}^{+}$efflux in guard cells under drought conditions (Figure 8). Therefore, the increased stomatal sensitivity to drought presumably resulted from KcTrxf-enhanced efflux of $\mathrm{K}^{+}$, although further investigation is needed to determine the effects of the KcTrxf-mediated signaling pathway on $\mathrm{K}^{+}$flux across the plasma membrane.

It is notable that KcTrxf increased ABA sensitivity in tobacco plants in terms of the stomatal response to the stress phytohormone (Figure 9). Drought generally increases the ABA level, which, in turn, activates the ABA signaling pathway in stress responses $[31,32,56]$. It has been shown that $A B A$ activates $\mathrm{K}^{+}$efflux channels in guard cells $[31,36]$. Thus, the increased $\mathrm{K}^{+}$efflux in KcTrxf-transgenic plants might be associated with drought-induced ABA.

Under conditions of drought stress, KcTrxf-transgenic plants displayed a significantly lower MDA content than WT and VC plants (Figure 7). This indicates that KcTrxf overexpression helps plants to alleviate drought-induced oxidative damage, since MDA is a marker of lipid peroxidation [12,13]. The oxidative injury to WT plants was mainly the result of high $\mathrm{H}_{2} \mathrm{O}_{2}$ levels in transgene plants under drought conditions (Figure 7). Similarly, drought resulted in an increase in $\mathrm{H}_{2} \mathrm{O}_{2}$ accumulation and lipid peroxidation [19-21]. The accumulation of ROS in water-stressed plants impairs the function of biochemical processes, damages organelles, and ultimately results in cell death [58]. The less-affected water status in $K c T r x f$-transgenic plants could limit $\mathrm{H}_{2} \mathrm{O}_{2}$ production, as water shortage resulted in oxidative burst under drought stress conditions [58]. Moreover, KcTrxf might directly participate in the control of ROS under drought conditions. KcTrxf contains a redox-active dithiol in its active site (Figure 2), allowing it to serve as a redox regulator in prokaryotic and eukaryotic organisms [15,52-54]. Identification of putative target proteins by proteomics revealed that thioredoxin $\mathrm{f} 1$ interacts with other antioxidative defense systems such as glutaredoxins (Grx) in the chloroplasts [59-61]. In this study, drought treatment caused a decline in GSH, but it increased the GSSG concentration in WT plants, indicating that GSH contributed to ROS scavenging under conditions of drought stress [17-19]. Compared with WT, GSH was less affected in drought-stressed plants, and the drought increase in GSSG/GSH was less pronounced in KcTrxf-transgenic lines (Table 1). This indicates that transgenic 
plants are more efficient at regenerating GSH from GSSG by GR under drought stress conditions [17,19]. We previously showed that KcTrxf-transgenic plants have increased GR activity in the chloroplast AsA-GSH cycle, which enables plants to maintain GSH levels under conditions of $\mathrm{NaCl}$ stress [13]. Therefore, antioxidative enzymes and antioxidants such as glutathione in the AsA-GSH cycle enable transgenic plants to retain ROS homeostasis under drought conditions $[17,19]$.

Soluble sugars play an important role in plant adaptation to water stress conditions [62]. Our data show that both glucose and fructose markedly increased in the KcTrxf-transgenic plants under drought stress conditions (Figure 10). This indicates that transgene plants could modify the osmolytes, allowing them to do osmotic adjustments to deal with drought stress [2,24]. The increased hexose concentration might result from starch degradation. Trx $\mathrm{f} 1$ has been shown to be involved in the regulation of starch degradation in Arabidopsis thaliana [47-49]. Thioredoxin-regulated $\beta$-amylase (BAM1) triggers diurnal starch degradation in guard cells and in mesophyll cells under osmotic stress conditions [48]. We noticed that the KcTrxf-transgenic plants displayed low sucrose levels under control and drought conditions (Figure 10). This suggests that KcTrxf affected the biosynthesis, storage, and mobilization of sucrose, since type-f thioredoxins have various functions in the mediation of carbon metabolism [15,45-49]. Glucose and fructose were found to increase $\mathrm{f}-$ and $\mathrm{m}$-type $\operatorname{Tr} x$ mRNA levels in Pisum sativum, while sucrose did not promote the expression of Trxs or even led to a decrease in the $\operatorname{Tr} x f$ gene [63]. Therefore, we suggest that the high hexose content relative to sucrose might be favorable for sustaining the expression of $\operatorname{Tr} x f$ and $m$ genes in transgenic plants over a long period of time.

\section{Materials and Methods}

\subsection{Plant Materials and Treatments}

Propagules of Kandelia candel (L.) Druce were collected from Dongzhai harbor in Hainan province in China (latitude $19^{\circ} 51^{\prime} \mathrm{N}$ and longitude $110^{\circ} 24^{\circ} \mathrm{E}$ ). The collected propagules were similar in size and were planted in individual 5-L pots containing sand in a greenhouse at Beijing Forestry University, China [9]. When the 4th pair of leaves came out, the seedlings were exposed to mannitol $(0,200 \mathrm{mM}$, $500 \mathrm{mM}$, and $1.0 \mathrm{M}$ ) in $500 \mathrm{~mL}$ of Hoagland nutrient solution for $8 \mathrm{~h}$ or 3 days. Then, the upper second leaves were immediately frozen in liquid $\mathrm{N}_{2}$ and stored at a freezer $\left(-80^{\circ} \mathrm{C}\right)$ for real-time quantitative polymerase chain reaction (RT-qPCR) analysis. Three biological replicates were used for RT-qPCR.

\subsection{Full-Length KcTrxf Gene Cloning and Sequence Analysis}

Total RNA was extracted from Kandelia candel leaves through a modified hot borate method [12]. RNA $(1 \mu \mathrm{g})$ was used as a template to synthesize first-strand cDNA with oligo (dT) primer (Promega, Madison, Wisconsin, USA) and M-MLV Reverse Transcriptase (Promega, Madison, Wisconsin, USA). The full-length cDNA sequence of KcTrxf was amplified with specific forward (5'-TCAGCTTGATCTAGCAATCT-3') and reverse primers (5'-TCAGCTTGATCTAGCAATCT- $\left.3^{\prime}\right)$ [13]. The gel-purified PCR products were then ligated to the PMD18-T (Takara, Kusatsu, Japan) vector for DNA sequencing.

Amino acid sequences of Trxfs from different plant species were compared with ClustalW2 (http://www.ebi.ac.uk/Tools/msa/clustalw2/) (EMBL-EBI, Hinxton, Cambridgeshire, UK). The phylogenetic tree of Trxs was constructed by the neighbor-joining method with 1000 bootstrap replicates using MEGA 6.0 software (http://www.megasoftware.net/index.php) (Center for Evolutionary Medicine and Informatics, Tempe, AZ, USA).

\subsection{Subcellular Localization Analysis}

Full-length cDNA was obtained by PCR using the primers Trxf-forward $5^{\prime}$-GGAATT CATGGCTGATTCAATTCTCT- $3^{\prime}$ and Trxf-reverse 5'-GGGGTACCCCGCTTTTCTAGCAATCTCA ATG-3' [13]. The sequence was designed to contain restriction sites (an EcoRI site at the 5' end and a 
KpnI site at the $3^{\prime}$ end) and to eliminate the termination codon. Then, PCR products were digested by EcoRI and KpnI and introduced into pEZS-NL, which does not express GFP well without adding a coding sequence to the $5^{\prime}$ end of the open reading frame (https://deepgreen.dpb.carnegiescience.edu/; https://deepgreen.dpb.carnegiescience.edu/cell.imaging.site/html/vectors.html) (Carnegie Institution for Science, Washington, DC, USA). Arabidopsis mesophyll protoplast isolation and polyethylene glycol-mediated transformation were performed essentially in accordance with Yoo et al. (2007) [64]. Confocal images were obtained with a confocal laser scanning microscope (Leica Microsystems GmbH, Wetzlar, Germany) after 16 to $20 \mathrm{~h}$ of incubation. The intensity of fluorescence was examined at 510-535 and 650-750 nm for GFP and chlorophyll, respectively. The confocal parameters were set as described in previous studies: the excitation wavelength was $488 \mathrm{~nm}$, and emission wavelength was 610-700 nm [65].

\subsection{Construction of KcTrxf-pro::GUS and Transformation to Arabidopsis}

The promoter region of KcTrxf (KcTrxf-pro) was isolated using the primers listed in Supplementary Materials Table S1 by hiTAIR-PCR, in accordance with the protocol described by Liu and Chen (2007) [66]. KcTrxf-pro was transferred into the pCambia1301 vector (forward 5'-GGAATTCCGGTCGTGGGTCCTCCTCCT-3' , reverse 5' -ACTGCCATGGTTTTGCCACTTGGGAA GAAAG- $3^{\prime}$ ). The promoter region of KcTrxf was merged with the GUS gene and introduced into Agrobacterium tumefacients 3101 with a freeze-thaw method [67]. The KcTrxf-pro::GUS construct was transformed to Arabidopsis plants by the floral-dip method [68]. Arabidopsis carrying pCambia1301 was used as a negative control. Seedlings were incubated at $37^{\circ} \mathrm{C}$ for $6 \mathrm{~h}$ with $1 \mathrm{~mL}$ of GUS substrate solution $\left(0.5 \mathrm{mg} \mathrm{ml}^{-1} \mathrm{X}\right.$-Gluc, $0.5 \mathrm{M}$ sodium phosphate buffer $\mathrm{pH} 7.0,1 \mathrm{mM}$ potassium ferrocyanide, $1 \mathrm{mM}$ ferricyanide, and $2 \%$ Triton-100). Green tissues were incubated in $70 \%$ ethanol for $24 \mathrm{~h}$ to remove chlorophyll. Samples were placed in 50\% glycerol and examined under a dissecting microscope.

\subsection{KcTrxf Expression and Purification of Recombinant Protein}

The cDNA sequences encoding the KcTrxf protein were amplified by PCR using primers with restriction sites (forward 5'-GGAATTCATGGCTTGATTCAATTCTCT-3', reverse 5'-CCGCT CGAGTCAGCTTGATCTAGCAATCT-3') and cloned into the pET28a expression vector EcoRI/XhoI sites. The recombinant mutant KcTrxf (amino acids 63-194) without the putative transit peptides was cloned into the EcoRI/XhoI sites of the pET28a expression vector. The resulting constructions were introduced into the Escherrichia coli BL21, and recombinant protein expression was induced by the addition of $0.1 \mathrm{mM}$ isopropylthythio- $\beta$-galactoside at $28^{\circ} \mathrm{C}$ overnight. The recombinant proteins were purified through $\mathrm{Ni}^{+}$affinity chromatography. Thereafter, the purified proteins were analyzed by SDS-PAGE.

\subsection{Trxf Activity Assay}

The purified KcTrxf recombinant protein was used to examine activity of Trx. Trx activity was assessed using the insulin reduction assays according to a modified protocol from Holmgren (1979) [55]. The incubation mixture contained 0,3 , or $5 \mu \mathrm{M}$ of $\mathrm{His}_{6}$-tagged KcTrxf protein in $100 \mathrm{mM}$ of potassium phosphate buffer at $\mathrm{pH} 7.0$ with $2 \mathrm{mM}$ of ethylenediaminetetraacetic acid (EDTA), $0.13 \mathrm{mM}$ of bovine insulin, and $0.25 \mathrm{mM}$ of dithiothreitol as a reductant. The turbidity of the reduced insulin chains was recorded at $650 \mathrm{~nm}$ for $30 \mathrm{~min}$. The Trxf activity measurements were repeated three times.

\subsection{KcTrxf Transformation in Tobacco}

Overexpression of KcTrxf in tobacco was performed as previously described [13]. In brief, the open reading frame (ORF) of KcTrxf was cloned and introduced into a donor vector-Dtop with the gateway methods. The cDNA in Dtop-Trx was introduced into PK7 to form the expression vector PK7-TRX. The construct was transformed to Agrobacterium tumefacients LBA 4404 with a freeze-thaw method [67]. The A. tumefacients strain was transferred to Nicotiana tabacum L. by the leaf-disc method $[13,67]$. The 
A. tumefacients-infected leaves were placed on MS without antibiotics for 2-3 days and transferred to MS supplemented with $50 \mathrm{mgL}^{-1}$ of kanamyein (Kan) and $100 \mathrm{mgL}^{-1}$ of carbenicillin (Carb). After 3-4 weeks, individual kanamycin-resistant shoots were selected and were cultured in MS medium without growth regulators or antibiotics. More than 20 independently transformed plants were screened for expression of KcTrxf [13], three of which with higher expression levels (L9, L10, and L21) were selected for further study. Then, plants were moved to soil to obtain seeds for further study. The soil-cultured plants were transferred to growth chambers with a $16 \mathrm{~h}$ photoperiod $\left(150 \mu \mathrm{mol} \mathrm{m} \mathrm{m}^{-2} \cdot \mathrm{s}^{-1}\right.$ irradiation, $21^{\circ} \mathrm{C}, 80 \%$ relative humidity).

\subsection{Real-Time Quantitative PCR}

The expression of KcTrxf in Kandelia candel and transgenic tobacco was analyzed using RT-qPCR with specific primers: forward 5'-TGGTTGCCATTGAGATTGC-3' and reverse 5'-CCCAA ATCGGAAGATGATA-3'. Total RNA was extracted from Kandelia candel from the second leaves of at least three different plants by a modified hot borate method [12], whereas the total RNA of Nicotiana tabacum was extracted from the second leaves of at least three independent plants using the Trizol method [13]. The first strand was synthesized from $2 \mu \mathrm{g}$ of total RNA using the RNase M-LV and oligo $\left(\mathrm{d}_{\mathrm{T}}\right) 12-15$ primer at $42{ }^{\circ} \mathrm{C}$ for $1 \mathrm{~h}$. The real-time $\mathrm{PCR}$ conditions were $10 \mathrm{~min}$ at $95^{\circ} \mathrm{C} ; 35$ cycles of $95^{\circ} \mathrm{C}$ for $30 \mathrm{~s}, 55^{\circ} \mathrm{C}$ for $30 \mathrm{~s}$, and $72{ }^{\circ} \mathrm{C}$ for $30 \mathrm{~s}$; followed by $10 \mathrm{~min}$ at $72{ }^{\circ} \mathrm{C}$. The endogenous housekeeping genes Tublin and EF1 $\alpha$ were used for Kandelia candel and Nicotiana tabacum, respectively. RT-qPCR was performed using the following primers: (i) Tubulin—forward 5'-TGCCCAAGGATGTGAACG-3', reverse 5'-CCATACCCTCACCCACAT-3'; (ii) EF1 $\alpha$-forward 5'-CTGTGAGGGACATGCGTCAAA-3', reverse $5^{\prime}$-GTAGTAGATCGCGAGTACCACCA-3'). The relative expression was quantified by MJ Opticon Montor software 3.1 (Bio-Rad Laboratories, Inc., Hercules, CA, USA). Three biological replicates were used for each round of RT-qPCR.

\subsection{Phenotype Tests to Assess Osmotic and Drought Tolerance}

Using genomic PCR, T2 generation of L9, L10, and L21 was checked for the presence of the KcTrxf gene. Seeds of wild-type (WT) and transgenic lines (L9, L10, and L21) were germinated on MS medium for 7 days and then subjected to $250 \mathrm{mM}$ of mannitol for 21 days. The root lengths and fresh weights of whole seedlings were measured in WT and transgenic lines. Twelve to 20 individual plants were used for each treatment. Four-week-old rooted plants of WT and transgenic lines were transferred to nursery soil for 4 weeks of acclimation and then exposed to drought by withdrawing water for 2 weeks. The water-retaining capacity, stomatal aperture, malondialdehyde (MDA) content, $\mathrm{H}_{2} \mathrm{O}_{2}$ production, soluble sugar content in leaves, and $\mathrm{K}^{+}$flux in guard cells were examined in control and stressed plants of WT and transgenic lines. All measurements were performed on the third or fourth fully expanded leaf.

\subsection{Determination of $M D A, \mathrm{H}_{2} \mathrm{O}_{2}, \mathrm{GSH}$, and GSSG}

Oxidative damage to lipids was determined by measuring the content of MDA according to the method described by Jing et al. (2015) [12] and Deng et al. (2015) [65]. Leaf samples (0.1 g) were frozen in liquid nitrogen and homogenized in $2 \mathrm{~mL}$ of $0.1 \%(w / v)$ thiobarbituric acid (TBA). The homogenate was centrifuged at 10,000 rpm for $5 \mathrm{~min}$. Then, $2 \mathrm{~mL}$ of $0.5 \%(w / v)$ TBA in $20 \%(v / v)$ trichloroacetic acid (TCA) was added to a $0.5-\mathrm{mL}$ aliquot of the supernatant. Samples were heated at $95^{\circ} \mathrm{C}$ for $30 \mathrm{~min}$ and then quickly cooled in an ice bath for $15 \mathrm{~min}$. After $10 \mathrm{~min}$ of centrifugation at $10,000 \mathrm{rpm}$ and $4{ }^{\circ} \mathrm{C}$, the absorbance was measured at 450,532, and $600 \mathrm{~nm}$, respectively. The content of $\mathrm{H}_{2} \mathrm{O}_{2}$ was measured by monitoring the $\mathrm{A}_{415}$ of the titanium peroxide complex. Absorbance values were calibrated to a standard curve generated with known concentrations of $\mathrm{H}_{2} \mathrm{O}_{2}$. Leaf samples from four individual plants were used for each treatment.

The GSH and GSSG contents were determined as described by Griffith (1980) [69]. Briefly, leaf samples $(0.1 \mathrm{~g})$ were frozen in liquid nitrogen and homogenized in $1 \mathrm{~mL}$ of $2.5 \mathrm{M} \mathrm{HClO}_{4}$ for 
$10 \mathrm{~min}$. Then, the homogenate was centrifuged at $10,000 \mathrm{rpm}$ for $10 \mathrm{~min}$ and the $\mathrm{pH}$ was adjusted 6.3-6.7 by $1.25 \mathrm{M} \mathrm{Na}_{2} \mathrm{CO}_{3}$. The GSH content in $1 \mathrm{~mL}$ of mixture $(100 \mu \mathrm{L}$ supernatant, $100 \mu \mathrm{L}$ of $6 \mathrm{mM} \mathrm{5,5-dithiobis-2-nitrobenzoic} \mathrm{acid} \mathrm{(DTNB),} 800 \mu \mathrm{L}$ of $0.3 \mathrm{mM}$ reduced nicotinamide adenine dinucleotide phosphate (NADPH), and glutathione reductase (GR, $1 \mathrm{U})$ ) was measured by monitoring the absorbance at $412 \mathrm{~nm}$. To determine the GSSG content, vinyl pyridine $(2 \mu \mathrm{L})$ was introduced to the supernatant and incubated for $1 \mathrm{~h}$. Then, the absorbance of the mixture was measured as described above. Absorbance values were calibrated to a standard curve generated with known concentrations of GSH.

\subsection{Water-Retaining Capacity}

Four-week-old rooted plants of WT and transgenic lines were transferred to nursery soil for 4 weeks of acclimation. Then, the upper mature leaves (the third to fifth leaves from the tip) were excised to measure the water-retaining capacity. Leaf samples were placed on a laboratory bench under a light intensity of $150-200 \mu \mathrm{mol} \mathrm{m}^{-1} \mathrm{~s}^{-1}$ at $25^{\circ} \mathrm{C}$ and a relative humidity of $40 \%$. Water loss from the leaf surface was measured during the period of $120 \mathrm{~min}$ air exposure [70]. Four individual plants were used for WT plants and each transgenic line.

\subsection{Stomatal Aperture Measurement}

The abaxial epidermis was carefully stripped from control and droughted plants of WT and transgenic lines. The stomatal apertures were measured under a microscope using the image processing software ImageJ (National Institutes of Health, Bethesda, MD, USA).

For ABA treatment, epidermal peels were stripped from WT and transgenic lines and floated in the opening solution (30 $\mathrm{mM} \mathrm{KCl}$ and $10 \mathrm{mM}$ 2-morpholinoethanesulfonic acid (MES)-KOH, pH 6.15) for $2.5 \mathrm{~h}$ under cool, white light. Then, ABA stock solution was added to the opening solution to reach a final concentration of $5 \mu \mathrm{M}$. The control was treated without the addition of ABA. After $2 \mathrm{~h}$ of ABA treatment, the stomatal apertures were measured as described above. One hundred stomata from four individual plants were used for WT and each transgenic line.

\subsection{3. $K^{+}$Flux in Guard Cells}

Tobacco leaves were sampled from control and droughted plants of WT and transgenic lines. The leaves were washed and rinsed with redistilled water. The abaxial epidermis was carefully stripped from the leaves, and epidermal peels were immediately incubated in measuring solution containing the following components (in $\mathrm{mM}$ ): $\mathrm{KCl}(0.5), \mathrm{CaCl}_{2}(0.1), \mathrm{MgCl}_{2}(0.1), \mathrm{NaCl}(0.1)$, and 2.5\% sucrose (the $\mathrm{pH}$ of the solution was adjusted to 5.8). After immobilization on the bottom of the chamber, steady flux profiles of $\mathrm{K}^{+}$in guard cells were recorded with the Noninvasive Micro-Test Technique (NMT-YG-100, Younger USA LLC, Amherst, MA, USA) with ASET 2.0 (Sciencewares, Falmouth, MA 02540, USA) and iFluxes 1.0 (Young-erUSA, LLC, Amherst, MA 01002, USA) software, which is capable of integrating and coordinating differential voltage signal collection, motion control, and image capture simultaneously. The $\mathrm{K}^{+}$flux was measured by shifting the ion-selective microelectrode between two sites close to the guard cells at a frequency in the range of $0.3-0.5 \mathrm{~Hz}$ [71]. For WT and each transgenic line, 30-40 stomata from four individual plants were used for control and drought treatment.

\subsection{Soluble Sugar Measurement}

Glucose, fructose, and sucrose were measured by the enzymatic method [72]. After being ground in liquid nitrogen, samples $(100 \mathrm{mg})$ were heated in triplicate at $80{ }^{\circ} \mathrm{C}$ for $20 \mathrm{~min}$ and centrifuged for $5 \mathrm{~min}$ at 14,000 rpm after successive addition of $500 \mu \mathrm{L}$ of $80 \%(\mathrm{v} / \mathrm{v})$ ethanol. Supernatants were combined, and the ethanol was removed by rotary evaporation. The residue was dissolved in $100 \mu \mathrm{L}$ of water and used for soluble sugar determination. A glucose (HK) assay kit was used for the determination (Sigma GAHK-20, Sigma-Aldrich, St. Louis, MO, USA)). Then, $10 \mu \mathrm{L}$ of $100 \mathrm{U}$ $\mathrm{mL}^{-1}$ phosphoglucomutase and $10 \mu \mathrm{L}$ of $100 \mu \mathrm{g} \mathrm{L}^{-1}$ invertase were added in succession to determine 
fructose and sucrose contents. For each treatment, 4-6 individual plants were used for WT and each transgenic line.

\subsection{Data Analysis}

All experimental data were analyzed using SPSS (version 19.0, IBM Corporation, Armonk, New York, USA) software. Statistical analyses were performed using one-way ANOVA. Unless otherwise stated, a $p$-value of less than 0.05 was considered statistically significant.

\section{Conclusions}

Mannitol treatment induced the expression of thioredoxin f, KcTrxf, in K. candel. Amino acid sequencing and phylogenetic analysis of the mangrove Trx classified it as an f-type Trx. Subcellular localization revealed that K. candel Trxf localized to chloroplasts. Enzymatic activity characterization revealed that the KcTrxf recombinant protein possessed Trx activity. KcTrxf overexpression contributed to osmotic and drought tolerance in tobacco. KcTrxf was shown to reduce the stomatal aperture by enhancing $\mathrm{K}^{+}$efflux under drought conditions, which increased the water-retaining capacity. Notably, the ABA sensitivity was increased in KcTrxf-transgenic tobacco, enabling the plants to sense and transduce stress signals after the onset of drought, thus limiting water loss through transpiration during prolonged periods of water stress. KcTrxf-transgenic plants had limited drought-induced $\mathrm{H}_{2} \mathrm{O}_{2}$ in leaves, which could reduce lipid peroxidation and retain the membrane integrity. In addition, GSH contributed to ROS scavenging and transgenic plants are more efficient at regenerating GSH from GSSG under conditions of drought stress. More importantly, KcTrxf-transgenic plants had increased glucose and fructose contents under drought stress conditions, most likely resulting from Trxf-promoted starch degradation under water stress. We conclude that KcTrxf contributes to osmotic and drought tolerance by increasing WRC, by enhancing osmotic adjustment, and by maintaining ROS homeostasis in transgenic plants. Therefore, KcTrxf has great potential for use in genetic transformation of drought susceptible species, for example, fast-growing poplars, which are used for large-scale plantations and afforestation in the dry lands of northern China.

Supplementary Materials: The following are available online at http:/www.mdpi.com/1422-0067/21/9/3335/s1, Table S1: Primer sequences used for cloning Kandelia candel Trxf promoter.

Author Contributions: X.J., J.Y., and S.C. conceived the original research project and selected methods. S.C. supervised the experiments. X.J., J.Y., X.M., Y.Z., Y.S., and M.X. performed most of the experiments. P.H., N.L., R.Z., J.L., and X.Z. provided technical assistance to X.J., J.Y., X.M., Y.Z., Y.S., and M.X. while X.J., J.Y., and X.M. designed the experiments and analyzed the data. X.J. refined the project and wrote the manuscript with contributions from all authors. S.C. revised the paper. All authors have read and agreed to the published version of the manuscript.

Funding: This research was supported jointly by the National Natural Science Foundation of China (grant nos. 31770643, 31570587, 31270654, and 31160150), the Beijing Municipal Natural Science Foundation (grant nos. 6182030 and 6172024), and the Fundamental Research Funds for the Central Universities (2019ZY25).

Acknowledgments: We thank the Functional Genomics Unit, Plant Systems Biology (Flanders Interuniversity Institute of Biotechnology, Ghent University) for providing the Gateway destination vectors.

Conflicts of Interest: The authors declare that the research was conducted in the absence of any commercial or financial relationships that could be construed as a potential conflict of interest.

\section{Abbreviations}

ABA

DTNB

EDTA

GR

GSH

GSSG

$\mathrm{H}_{2} \mathrm{O}_{2}$ abscisic acid

5, 5-dithiobis-2-nitrobenzoic acid

ethylenediaminetetraacetic acid

glutathione reductase

reduced glutathione

oxidized glutathione

hydrogen peroxide 


$\begin{array}{ll}\text { MDA } & \text { malondialdehyde } \\ \text { MDAR } & \text { monodehydroascorbate reductase } \\ \text { MS } & \text { 2-morphige-Skoog medium } \\ \text { MES } & \text { reduced nicotinamide adenine dinucleotide phosphate } \\ \text { NADPH } & \text { noninvasive micro-test technique } \\ \text { NMT } & \text { nonprotein thiols } \\ \text { NPTs } & \text { open reading frame } \\ \text { ORF } & \text { real-time quantitative PCR } \\ \text { RT-qPCR } & \text { reactive oxygen species } \\ \text { ROS } & \text { superoxide dismutase } \\ \text { SOD } & \text { plasma membrane } \\ \text { PM } & \text { thioredoxin } \\ \text { TRX } & \text { thiobarbituric acid } \\ \text { TBA } & \text { trichloroacetic acid } \\ \text { TCA } & \text { water-retaining capacity } \\ \text { WRC } & \end{array}$

\section{References}

1. Valliyodan, B.; Nguyen, H.T. Understanding regulatory networks and engineering for enhanced drought tolerance in plants. Curr. Opin. Plant Biol. 2006, 9, 189-195. [CrossRef] [PubMed]

2. Polle, A.; Chen, S.; Eckert, C.; Harfouche, A. Engineering drought resistance in forest trees. Front. Plant Sci. 2019, 9, 1875.

3. Allen, C.D.; Macalady, A.K.; Chenchouni, H.; Bachelet, D.; McDowell, N.; Vennetier, M.; Thomas, K.; Riglingh, A.; Breshearsi, D.D.; Hogg, E.H.; et al. A global overview of drought and heat-induced tree mortality reveals emerging climate change risks for forests. For. Ecol. Manag. 2010, 259, 660-684. [CrossRef]

4. Reyer, C.P.O.; Brouwers, N.; Rammig, A.; Brook, B.W.; Epila, J.; Grant, R.F.; Holmgren, M.; Langerwisch1, F.; Leuzinger, S.; Lucht, W.; et al. Forest resilience and tipping points at different spatio-temporal scales: Approaches and challenges. J. Ecol. 2015, 103, 5-15. [CrossRef]

5. Mendez-Alonzo, R.; Lopez-Portillo, J.; Moctezuma, C.; Bartlett, M.K.; Sack, L. Osmotic and hydraulic adjustment of mangrove saplings to extreme salinity. Tree Physiol. 2016, 36, 1562-1572. [CrossRef]

6. Zhu, Z.; Zhang, R.; Liu, T.; Zheng, H. Solute accumulation and osmotic adjustment characteristics of the mangrove Avicennia marina under NaCl-induced salinity stress. Bot. Mar. 2011, 54, 335-341. [CrossRef]

7. Parida, A.K.; Das, A.B.; Mittra, B. Effects of salt on growth, ion accumulation, photosynthesis and leaf anatomy of the mangrove, Bruguiera parviflora. Trees 2004, 18, 167-174. [CrossRef]

8. Oh, D.H.; Dassanayake, M.; Bohnert, H.J.; Cheeseman, J.M. Life at the extreme: Lessons from the genome. Genome Biol. 2012, 13, 241. [CrossRef]

9. Li, N.; Chen, S.; Zhou, X.; Li, C.; Shao, J.; Wang, R.; Fritz, E.; Hüttermann, A.; Polle, A. Effect of $\mathrm{NaCl}$ on photosynthesis, salt accumulation and ion compartmentation in two mangrove species, Kandelia candel and Bruguiera gymnorhiza. Aquat. Bot. 2008, 88, 303-310. [CrossRef]

10. Lu, Y.; Li, N.; Sun, J.; Hou, P.; Jing, X.; Zhu, H.; Deng, S.; Han, Y.; Huang, X.; Ma, X.; et al. Exogenous hydrogen peroxide, nitric oxide and calcium mediate root ion fluxes in two non-secretor mangrove species subjected to $\mathrm{NaCl}$ stress. Tree Physiol. 2013, 33, 81-95. [CrossRef]

11. Lang, T.; Sun, H.; Li, N.; Lu, Y.; Shen, Z.; Jing, X.; Xiang, M.; Shen, X.; Chen, S. Multiple signaling networks of extracellular ATP, hydrogen peroxide, calcium, and nitric oxide in the mediation of root ion fluxes in secretor and non-secretor mangroves under salt stress. Aquat. Bot. 2014, 119, 33-43. [CrossRef]

12. Jing, X.; Hou, P.; Lu, Y.; Deng, S.; Li, N.; Zhao, R.; Sun, J.; Wang, Y.; Han, Y.; Lang, T.; et al. Overexpression of copper/zinc superoxide dismutase from mangrove Kandelia candel in tobacco enhances salinity tolerance by the reduction of reactive oxygen species in chloroplast. Front. Plant Sci. 2015, 6, 23. [CrossRef] [PubMed]

13. Jing, X.; Sun, Y.; Xiang, M.; Qian, Z.; Lang, T.; Zhao, R.; Shen, X.; Chen, S. Overexpression of KcTrxf in tobacco enhances salt tolerance through the regulation of ROS homeostasis under $\mathrm{NaCl}$ stress. J. Beijing For. Univ. $2015,37,17-26$. 
14. Li, N.; Zhou, X.; Wang, R.; Li, J.; Lu, C.; Chen, S. Salt compartmentation and antioxidant defense in roots and leaves of two non-salt secretor mangroves under salt stress. In Mangrove Ecosystem Ecology and Function; Sahadev, S., Ed.; IntechOpen Limited: London, UK, 2018; pp. 81-104.

15. Geigenberger, P.; Thormalen, I.; Daloso, D.M.; Fernie, A.R. The unprecedented versatility of the plant thioredoxin system. Trends Plant Sci. 2017, 22, 249-262. [CrossRef]

16. Polle, A. Dissecting the superoxide dismutase-ascorbate-glutathione pathway by metabolic modeling: Computer analysis as a step towards flux analysis. Plant Physiol. 2001, 126, 445-462. [CrossRef]

17. Bartoli, C.G.; Buet, A.; Grozeff, G.G.; Galatro, A.; Simontacchi, M. Ascorbate-glutathione cycle and abiotic stress tolerance in plants. In Ascorbic Acid in Plant Growth, Development and Stress Tolerance; Hossain, M., Munné-Bosch, S., Burritt, D., Diaz-Vivancos, P., Fujita, M., Lorence, A., Eds.; Springer: Cham, Switzerland, 2017; pp. 177-200.

18. Yan, Y.; Pan, C.; Du, Y.; Li, D.; Liu, W. Exogenous salicylic acid regulates reactive oxygen species metabolism and ascorbate-glutathione cycle in Nitraria tangutorum Bobr. under salinity stress. Physiol. Mol. Biol. Plants 2018, 24, 577-589. [CrossRef]

19. Choudhury, F.K.; Rivero, R.M.; Blumwald, E.; Mittler, R. Reactive oxygen species, abiotic stress and stress combination. Plant. J. 2017, 90, 856-867. [CrossRef]

20. Hasanuzzaman, M.; Nahar, K.; Gill, S.S.; Fujita, M. Drought stress responses in plants, oxidative stress, and antioxidant defense. In Climate Change and Plant Abiotic Stress Tolerance; Narendra, T., Sarvajeet, S.G., Eds.; Wiley-VCH Verlag GmbH \& Co. KGaA: Weinheim, Germany, 2013; pp. 209-250.

21. Sadeghi, F.; Samsampour, D.; Seyahooei, M.A.; Bagheri, A.; Soltani, J. Fungal endophytes alleviate drought-induced oxidative stress in mandarin (Citrus reticulata L.): Toward regulating the ascorbateglutathione cycle. Sci. Hortic. 2020, 261, 108991. [CrossRef]

22. Buckley, T.N. The control of stomata by water balance. New Phytol. 2005, 168, 275-292. [CrossRef]

23. Daszkowska-Golec, A.; Szarejko, I. Open or close the gate-stomata action under the control of phytohormones in drought stress conditions. Front. Plant Sci. 2013, 4, 138. [CrossRef]

24. Harfouche, A.; Meilan, R.; Altman, A. Molecular and physiological responses to abiotic stress in forest trees and their relevance to tree improvement. Tree Physiol. 2014, 34, 1181-1198. [CrossRef] [PubMed]

25. Brodribb, T.J.; Holbrook, N.M. Stomatal closure during leaf dehydration, correlation with other leaf physiological traits. Plant Physiol. 2003, 132, 2166-2173. [CrossRef] [PubMed]

26. Araújo, W.L.; Fernie, A.R.; Nunes-Nesi, A. Control of stomatal aperture: A renaissance of the old guard. Plant Signal Behav. 2011, 6, 1305-1311. [CrossRef]

27. Chen, S.; Wang, S.; Altman, A.; Hüttermann, A. Genotypic variation in drought tolerance of poplar in relation to abscisic acid. Tree Physiol. 1997, 17, 797-803. [CrossRef] [PubMed]

28. Chen, S.; Li, J.; Wang, S.; Hüttermann, A.; Altman, A. Salt, nutrient uptake and transport and ABA of Populus euphratica; a hybrid in response to increasing soil NaCl. Trees 2001, 15, 186-194. [CrossRef]

29. Chen, S.; Li, J.; Wang, T.; Wang, S.; Polle, A.; Hüttermann, A. Osmotic stress and ion-specific effects on xylem abscisic acid and the relevance to salinity tolerance in poplar. J. Plant Growth Regul. 2002, 21, 224-233. [CrossRef]

30. Chang, Y.; Chen, S.; Yin, W.; Wang, R.; Liu, Y.; Shi, Y.; Shen, Y.; Li, Y.; Jiang, J.; Liu, Y. Growth, gas exchange, abscisic acid, and calmodulin response to salt stress in three poplars. J. Integr. Plant Biol. 2006, 48, $286-293$. [CrossRef]

31. Pantin, F.; Monnet, F.; Jannaud, D.; Costa, J.M.; Renaud, J.; Muller, B.; Genty, B. The dual effect of abscisic acid on stomata. New Phytol. 2013, 197, 65-72. [CrossRef]

32. Fujii, H.; Chinnusamy, V.; Rodrigues, A.; Rubio, S.; Antoni, R.; Park, S.Y.; Cutler, S.R.; Sheen, J.; Rodriguez, P.L.; Zhu, J.K. In vitro reconstitution of an abscisic acid signalling pathway. Nature 2009, 462, 660-664. [CrossRef]

33. Hedrich, R. Ion channels in plants. Physiol. Rev. 2012, 92, 1777-1811. [CrossRef]

34. Homann, U.; Thiel, G. The number of $\mathrm{K}^{+}$channels in the plasma membrane of guard cell protoplasts changes in parallel with the surface area. Proc. Natl. Acad. Sci. USA 2002, 99, 10215-10220. [CrossRef]

35. Prodhan, M.Y.; Munemasa, S.; Nahar, M.N.E.N.; Nakamura, Y.; Murata, Y. Guard cell salicylic acid signaling is integrated into abscisic acid signaling via the $\mathrm{Ca}^{2+} / \mathrm{CPK}$-dependent pathway. Plant Physiol. 2018, 178, 441-450. [CrossRef] [PubMed]

36. Schroeder, J.I.; Allen, G.J.; Hugouvieux, V.; Kwak, J.M.; Waner, D. Guard cell signal transduction. Annu. Rev. Plant Biol. 2001, 52, 627-658. [CrossRef] [PubMed] 
37. de Dios Barajas-Lopez, J.; Serrato, A.J.; Olmedilla, A.; Chueca, A.; Sahrawy, M. Localization in roots and flowers of pea chloroplastic thioredoxin $f$ and thioredoxin $m$ proteins reveals new roles in nonphotosynthetic organs. Plant Physiol. 2007, 145, 946-960. [CrossRef]

38. Janz, D.; Polle, A. Harnessing salt for woody biomass production. Tree Physiol. 2012, 32, 1-3. [CrossRef] [PubMed]

39. Bogeat-Triboulot, M.B.; Brosché, M.; Renaut, J.; Jouve, L.; Thiec, D.L.; Fayyaz, P.; Vinocur, B.; Witters, E.; Laukens, K.; Teichmann, T.; et al. Gradual soil water depletion results in reversible changes of gene expression, protein profiles, ecophysiology, and growth performance in Populus euphratica, a poplar growing in arid regions. Plant Physiol. 2007, 143, 876-892. [CrossRef]

40. Brosché, M.; Vinocur, B.; Alatalo, E.R.; Lamminmäki, A.; Teichmann, T.; Ottow, E.A.; Djilianov, D.; Afif, D.; Bogeat-Triboulot, M.B.; Altman, A.; et al. Gene expression and metabolite profiling of Populus euphratica growing in the Negev desert. Genome Biol. 2005, 6, R101. [CrossRef]

41. Ottow, E.A.; Brinker, M.; Teichmann, T.; Fritz, E.; Kaiser, W.; Brosché, M.; Kangasjärvi, J.; Jiang, X.; Polle, A. Populus euphratica displays apoplastic sodium accumulation, osmotic adjustment by decreases in calcium and soluble carbohydrates, and develops leaf succulence under salt stress. Plant Physiol. 2005, 139, 1762-1772. [CrossRef]

42. Dluzniewska, P.; Gessler, A.; Dietrich, H.; Schnitzler, J.-P.; Teuber, M.; Rennenberg, H. Nitrogen uptake and metabolism in Populus $\times$ canescens as affected by salinity. New Phytol. 2007, 173, 279-293. [CrossRef] [PubMed]

43. Ehlting, B.; Dluzniewska, P.; Dietrich, H.; Selle, A.; Teuber, M.; Hänsch, R.; Nehls, U.; Polle, A.; Schnitzler, J.P.; Rennenberg, H.; et al. Interaction of nitrogen nutrition and salinity in Grey poplar (Populus tremula $\times$ alba). Plant Cell Environ. 2007, 30, 796-811. [CrossRef] [PubMed]

44. Pallara, G.; Giovannelli, A.; Traversi, M.L.; Camussi, A.; Racchi, M.L. Effect of water deficit on expression of stress-related genes in the cambial region of two contrasting poplar clones. J. Plant Growth Regul. 2012, 31, 102-112. [CrossRef]

45. Sanz-Barrio, R.; Corral-Martinez, P.; Ancin, M.; Segui-Simarro, J.M.; Farran, I. Overexpression of plastidial thioredoxin $\mathrm{f}$ leads to enhanced starch accumulation in tobacco leaves. Plant Biotechnol. J. 2013, 11, 618-627. [CrossRef]

46. Thormählen, I.; Ruber, J.; von Roepenack-Lahaye, E.; Ehrlich, S.M.; Massot, V.; Hümmer, C.; Tezycka, J.; Issakidis-Bourguet, E.; Geigenberger, P. Inactivation of thioredoxin $f 1$ leads to decreased light activation of ADP-glucose pyrophosphorylase and altered diurnal starch turnover in leaves of Arabidopsis plants. Plant Cell Environ. 2013, 36, 16-29. [CrossRef] [PubMed]

47. Sparla, F.; Costa, A.; Lo Schiavo, F.; Pupillo, P.; Paolo, T. Redox regulation of a novel plastid-targeted-amylase of Arabidopsis. Plant Physiol. 2006, 141, 840-850. [CrossRef] [PubMed]

48. Valerio, C.; Costa, A.; Marri, L.; Issakidis-Bourguet, E.; Pupillo, P.; Trost, P.; Sparla, F. Thioredoxin-regulated $\beta$-amylase (BAM1) triggers diurnal starch degradation in guard cells, and in mesophyll cells under osmotic stress. J. Exp. Bot. 2011, 62, 545-555. [CrossRef] [PubMed]

49. Seung, D.; Thalmann, M.; Sparla, F.; Abou Hachem, M.; Lee, S.K.; Issakidis-Bourguet, E.; Svensson, B.; Zeeman, S.C.; Santelia, D. Arabidopsis thaliana AMY3 is a unique redox-regulated chloroplastic $\alpha$-amylase. J. Biol. Chem. 2013, 288, 33620-33633. [CrossRef]

50. Emanuelsson, O.; Brunak, S.; Von Heijne, G.; Nielsen, H. Locating proteins in the cell using TargetP, SignalP and related tools. Nat. Protoc. 2007, 2, 953. [CrossRef]

51. Emanuelsson, O.; Nielsen, H.; Von Heijne, G. ChloroP, a neural network-based method for predicting chloroplast transit peptides and their cleavage sites. Protein Sci. 1999, 8, 978-984. [CrossRef]

52. Buchanan, B.B.; Balmer, Y. Redox regulation: A broadening horizon. Annu. Rev. Plant Biol. 2005, 56, 187-220. [CrossRef]

53. Schürmann, P.; Buchanan, B.B. The ferredoxin/thioredoxin system of oxygenic photosynthesis. Antioxid. Redox Signal. 2008, 10, 1235-1274. [CrossRef]

54. Meyer, Y.; Siala, W.; Bashandy, T.; Riondet, C.; Vignols, F.; Reichheld, J.P. Glutaredoxins and thioredoxins in plants. Biochim. Biophys. Acta 2008, 1783, 589-600. [CrossRef] [PubMed]

55. Holmgren, A. Thioredoxin catalyzes the reduction of insulin disulfides by dithiothreitol and dihydrolipoamide. J. Biol. Chem. 1979, 254, 9627-9632. 
56. Fujita, Y.; Fujita, M.; Shinozaki, K.; Yamaguchi-Shinozaki, K. ABA-mediated transcriptional regulation in response to osmotic stress in plants. J. Plant Res. 2011, 124, 509-525. [CrossRef] [PubMed]

57. Daloso, D.M.; Dos Anjos, L.; Fernie, A.R. Roles of sucrose in guard cell regulation. New Phytol. 2016, 211, 809-818. [CrossRef] [PubMed]

58. Das, K.; Roychoudhury, A. Reactive oxygen species (ROS) and response of antioxidants as ROS scavengers during environmental stress in plants. Front. Environ. Sci. 2014, 2, 53. [CrossRef]

59. Meyer, Y.; Belin, C.; Delorme-Hinoux, V.; Reichheld, J.P.; Riondet, C. Thioredoxin and glutaredoxin systems in plants: Molecular mechanisms, crosstalks, and functional significance. Antioxid. Redox Signal. 2012, 17, 1124-1160. [CrossRef]

60. Lemaire, S.D.; Michelet, L.; Zaffagnini, M.; Massot, V.; Issakidis-Bourguet, E. Thioredoxins in chloroplasts. Curr. Genet. 2007, 51, 343-365. [CrossRef]

61. Lindahl, M.; Kieselbach, T. Disulfide proteomes and interactions with thioredoxin on the track towards understanding redox regulation in chloroplasts and cyanobacteria. J. Proteomics. 2009, 72, 416-438. [CrossRef]

62. Thalmann, M.; Santelia, D. Starch as a determinant of plant fitness under abiotic stress. New Phytol. 2017, 214, 943-951. [CrossRef]

63. de Dios Barajas-Lopez, J.; Tezycka, J.; Travaglia, C.N.; Serrato, A.J.; Chueca, A.; Thormählen, I.; Geigenberger, P.; Sahrawy, M. Expression of the chloroplast thioredoxins $f$ and $m$ is linked to short-term changes in the sugar and thiol status in leaves of Pisum sativum. J. Exp. Bot. 2012, 63, 4887-4900. [CrossRef]

64. Yoo, S.D.; Cho, Y.H.; Sheen, J. Arabidopsis mesophyll protoplasts: A versatile cell system for transient gene expression analysis. Nat. Protoc. 2007, 2, 1565. [CrossRef] [PubMed]

65. Deng, S.; Sun, J.; Zhao, R.; Ding, M.; Zhang, Y.; Sun, Y.; Wang, W.; Tan, Y.; Liu, D.; Ma, X.; et al. Populus euphratica APYRASE2 enhances cold tolerance by modulating vesicular trafficking and extracellular ATP in Arabidopsis plants. Plant Physiol. 2015, 169, 530-548. [CrossRef] [PubMed]

66. Liu, Y.G.; Chen, Y. High-efficiency thermal asymmetric interlaced PCR for amplification of unknown flanking sequences. Biotechniques 2007, 43, 649-656. [CrossRef] [PubMed]

67. Shen, Z.; Yao, J.; Sun, J.; Chang, L.; Wang, S.; Ding, M.; Qian, Z.; Zhang, H.; Zhao, N.; Sa, G.; et al. Populus euphratica HSF binds the promoter of WRKY1 to enhance salt tolerance. Plant Sci. 2015, 235, 89-100. [CrossRef] [PubMed]

68. Clough, S.J.; Bent, A.F. Floral dip: A simplified method for Agrobacterium-mediated transformation of Arabidopsis thaliana. Plant J. 1998, 16, 735-743. [CrossRef]

69. Griffith, O.W. Determination of glutathione and glutathione disulfide using glutathione reductase and 2-vinylpyridine. Anal. Biochem. 1980, 106, 207-212. [CrossRef]

70. Han, Y.; Wang, W.; Sun, J.; Ding, M.; Zhao, R.; Deng, S.; Wang, F.; Hu, Y.; Wang, Y.; Lu, Y.; et al. Populus euphratica XTH overexpression enhances salinity tolerance by the development of leaf succulence in transgenic tobacco plants. J. Exp. Bot. 2013, 64, 4225-4238. [CrossRef]

71. Sun, J.; Dai, S.; Wang, R.; Chen, S.; Li, N.; Zhou, X.; Lu, C.; Shen, X.; Zheng, X.; Hu, Z.; et al. Calcium mediates root $\mathrm{K}^{+} / \mathrm{Na}^{+}$homeostasis in poplar species differing in salt tolerance. Tree Physiol. 2009, 29, 1175-1186. [CrossRef]

72. Fernie, A.R.; Roscher, A.; Ratcliffe, R.G.; Kruger, N.J. Fructose 2,6-bisphosphate activates pyrophosphate: Fructose-6-phosphate 1-phosphotransferase and increases triose phosphate to hexose phosphate cycling in heterotrophic cells. Planta 2001, 212, 250-263. [CrossRef]

(C) 2020 by the authors. Licensee MDPI, Basel, Switzerland. This article is an open access article distributed under the terms and conditions of the Creative Commons Attribution (CC BY) license (http://creativecommons.org/licenses/by/4.0/). 